\title{
Evaluating the potential of poly(beta-amino ester) nanoparticles for reprogramming human fibroblasts to become induced pluripotent stem cells
}

\author{
This article was published in the following Dove Press journal: \\ International Journal of Nanomedicine \\ 3 December 2013 \\ Number of times this article has been viewed
}

\author{
Nupura S Bhise ${ }^{1, *}$ \\ Karl J Wahlin ${ }^{2, *}$ \\ Donald J Zack ${ }^{2-4}$ \\ Jordan J Green ${ }^{1,2}$ \\ 'Department of Biomedical \\ Engineering, Translational Tissue \\ Engineering Center, and Institute for \\ Nanobiotechnology, ${ }^{2}$ Department of \\ Ophthalmology, The Johns Hopkins \\ University School of Medicine, \\ Baltimore, MD, ${ }^{3}$ Solomon H Snyder \\ Department of Neuroscience, \\ Department of Molecular Biology \\ and Genetics, and Institute of \\ Genetic Medicine, The Johns Hopkins \\ University School of Medicine, \\ Baltimore, MD, USA; ${ }^{4}$ nstitut de la \\ Vision, Paris, France \\ *These authors contributed equally \\ to this work
}

Background: Gene delivery can potentially be used as a therapeutic for treating genetic diseases, including neurodegenerative diseases, as well as an enabling technology for regenerative medicine. A central challenge in many gene delivery applications is having a safe and effective delivery method. We evaluated the use of a biodegradable poly(beta-amino ester) nanoparticle-based nonviral protocol and compared this with an electroporation-based approach to deliver episomal plasmids encoding reprogramming factors for generation of human induced pluripotent stem cells (hiPSCs) from human fibroblasts.

Methods: A polymer library was screened to identify the polymers most promising for gene delivery to human fibroblasts. Feeder-independent culturing protocols were developed for nanoparticle-based and electroporation-based reprogramming. The cells reprogrammed by both polymeric nanoparticle-based and electroporation-based nonviral methods were characterized by analysis of pluripotency markers and karyotypic stability. The hiPSC-like cells were further differentiated toward the neural lineage to test their potential for neurodegenerative retinal disease modeling.

Results: 1-(3-aminopropyl)-4-methylpiperazine end-terminated poly(1,4-butanediol diacrylate-co-4-amino-1-butanol) polymer (B4S4E7) self-assembled with plasmid DNA to form nanoparticles that were more effective than leading commercially available reagents, including Lipofectamine $^{\circledR} 2000, \mathrm{FuGENE}^{\circledR} \mathrm{HD}$, and $25 \mathrm{kDa}$ branched polyethylenimine, for nonviral gene transfer. B4S4E7 nanoparticles showed effective gene delivery to IMR-90 human primary fibroblasts and to dermal fibroblasts derived from a patient with retinitis pigmentosa, and enabled coexpression of exogenously delivered genes, as is needed for reprogramming. The karyotypically normal hiPSC-like cells generated by conventional electroporation, but not by poly(beta-amino ester) reprogramming, could be differentiated toward the neuronal lineage, specifically pseudostratified optic cups.

Conclusion: This study shows that certain nonviral reprogramming methods may not necessarily be safer than viral approaches and that maximizing exogenous gene expression of reprogramming factors is not sufficient to ensure successful reprogramming.

Keywords: poly(beta-amino ester) nanoparticles, reprogramming, human fibroblasts, induced pluripotent stem cells

\section{Introduction}

Retinitis pigmentosa is a heterogeneous group of inherited retinal degenerative diseases that result in vision loss due to the dysfunction and death of retinal photoreceptor cells. ${ }^{1}$ Most forms of retinitis pigmentosa are currently untreatable. The lack of an effective 
cure to reverse vision loss has led to a heightened interest in regenerative medicine approaches using stem cells as therapeutic agents. ${ }^{2}$ Cell transplantation therapy to repair or replace damaged and lost photoreceptors has the potential to effectively treat some forms of retinitis pigmentosa.

Reprogramming human differentiated cells into induced pluripotent stem cells (iPSCs) could potentially enable a patient to receive a customized cell therapy of any cell type that is a perfect genetic match. ${ }^{3,4}$ Moreover, these cells can help recapitulate the disease condition in vitro for studying the pathophysiology of the disease as well as drug screening. The use of viral vectors raises serious clinical safety concerns, as has been tragically demonstrated in several gene therapy clinical trials. ${ }^{5-8}$ Recent efforts have thus focused on nonviral methods as a potentially safer alternative. iPSCs have been nonvirally generated using electroporation of nonintegrating episomal plasmids, ${ }^{4,9,10}$ small molecule modulators, ${ }^{11}$ minicircle DNA vectors, ${ }^{12}$ recombinant proteins, ${ }^{13,14}$ and synthetic messenger (m)RNA technology..$^{15}$

Although promising, these approaches report low reprogramming efficacy, and protocols involving animal-origin feeder cells and conditioned media containing serum may raise safety concerns for translation. ${ }^{4}$ In addition, some of these methods have only been demonstrated in easily amenable somatic cell types, ${ }^{10}$ and in some studies the resulting cells were incompletely reprogrammed. ${ }^{16}$ New biomaterials that can safely and effectively deliver nucleic acids could potentially enable the generation of cells expressing defined factors in defined amounts for transplantation therapy to repair/replace a malfunctioning gene. This technology could potentially enable the reprogramming of human adult primary cells into human pluripotent stem cells that may offer a replenishable source of autologous cells for drug testing, disease research, and cell therapy.

Commercially available nonviral reagents such as FuGENE ${ }^{\circledR}$ HD (Roche, Basel, Switzerland) and Lipofectamine $^{\circledR} 2000$ (Invitrogen, Carlsbad, CA, USA) are routinely used in cell biology research, yet often exhibit lower efficacy and higher cytotoxicity than desired. ${ }^{17-19}$ Cationic polymers condense DNA into nanoparticles via electrostatic interaction with the negatively charged DNA backbone. Poly(beta-amino ester)s (PBAEs) are a newer class of biodegradable polymeric vectors ${ }^{20}$ that can complex with DNA, promote cellular uptake, facilitate endosomal escape, and allow for DNA release in the cytoplasm and subsequent transport to the nucleus. We have synthesized new PBAEs and used them to develop highly effective nonviral nanoparticle-based gene delivery systems. ${ }^{21}$ For some human primary cells, these polymers are comparable with viruses in terms of gene delivery efficacy. ${ }^{22}$

Polymeric nanoparticle-based nonviral gene delivery technology has the potential to offer a safe and effective means of generating genetically matched human iPSCs from human fibroblasts in a feeder-independent manner. These reprogrammed human cells could then potentially be used as new stem cell lines for research purposes including in vitro disease modeling that would offer a platform to study drugs that could target the cellular dysfunction itself. Because these cells would be created without the use of viruses, they may be safer for cell transplantation and clinical use.

In this study, we explored the use of polymeric nanoparticle-based nonviral gene delivery to achieve feederindependent reprogramming of human fetal lung fibroblasts using a combination of three episomal plasmids, with the goal of utilizing the resulting cells for disease modeling of retinitis pigmentosa. A library of next-generation biodegradable cationic polymers useful for creating effective gene delivery nanoparticles was developed to transfect human fibroblasts. Subsequently, a polymeric nanoparticle reprogramming protocol was developed and optimized, and the resulting protocol was then compared with an electroporation-based protocol in terms of reprogramming efficacy and the neuronal differentiation capacity of the generated human iPSC-like cells.

\section{Materials and methods Cell culture}

\section{Human fibroblasts}

IMR-90 human fetal lung fibroblast cells (American Type Culture Collection, Manassas, VA, USA) were propagated following protocols and reagents recommended by the American Type Culture Collection. Specifically, IMR90 cells were grown in Eagle's Minimum Essential Medium (American Type Culture Collection) supplemented with 10\% fetal bovine serum (American Type Culture Collection) and 100 units of penicillin and streptomycin. IMR-90 cells were fed every other day, subcultured upon confluence, and used prior to passage 8. Patient-derived dermal fibroblasts were donated with informed consent for this research, which was approved by The Johns Hopkins Medicine institutional review board. Adult dermal fibroblasts derived from a patient with retinitis pigmentosa were obtained from a skin biopsy sample by digestion in medium comprised of Dulbecco's Modified Eagle's Medium (DMEM) with 20\% fetal bovine serum, $0.25 \%$ collagenase type I, $0.25 \%$ Trypsin, $0.05 \%$ DNAse I, and $1 \%$ penicillin-streptomycin. Thereafter, cells were grown 
in DMEM containing 20\% fetal calf serum, $1 \times$ nonessential amino acids, $1 \mathrm{mM}$ pyruvate, and $1 \times$ antibiotic-antimycotic (Life Technologies, Grand Island, NY, USA). A week prior to electroporation or PBAE transfection, fibroblasts were grown on Matrigel-coated tissue culture flasks and subcultured at a high density to maintain them in a log phase of cell division. To maintain a maximal growth rate, the cells were passaged prior to reaching confluence.

\section{Human iPSC-like cells}

Human iPSC-like cells were maintained in mTeSR1 (Stem Cell Technologies, Vancouver, BC, Canada) medium on feeder-independent growth factor-reduced Matrigel substrate. The cells were pretreated with blebbistatin to inhibit myosin II, a downstream effector in the Rho-associated protein kinase (ROCK) pathway, and passaged as a singlecell suspension following 5-7 minutes of treatment with Accutase $^{\circledR}$ (Sigma-Aldrich, St Louis, MO, USA). The cells were subsequently rinsed in DMEM:F12, resuspended in $\mathrm{mTeSR} 1$, and plated at a density of $1 \times 10^{4}$ per $35 \mathrm{~mm}$ dish. Blebbistatin was used to increase cell survival during the first 24 hours. Care was taken to reduce exposure of the mTeSR 1 medium to light and high temperature.

\section{Reporter plasmids for transfection studies and episomal plasmids for reprogramming studies}

The two reporter plasmids used in this study, ie, plasmid with luciferase gene controlled by cytomegalovirus promoter (CMV-Luc) and enhanced green fluorescent protein plasmid (EGFP-N1, $4.7 \mathrm{~kb}$ ), were obtained from Elim Biopharmaceuticals (Hayward, CA, USA). The CMV-Luc reporter plasmid contains the coding sequence of firefly luciferase driven by a CMV promoter, and the EGFP-N1 plasmid contains the coding sequence for green fluorescent protein driven by a CMV promoter. The three Epstein-Barr nuclear antigen-1/plasmid origin of replication (EBNA-1/oriP) episomal plasmids used in this study, pEP4EO2SEN2K (16.2 kb), pEP4EO2SET2K $(17.5 \mathrm{~kb})$, and pCEP4-M2L (12.8 kb), were obtained from Addgene (Cambridge, MA, USA) and originally developed by the Thomson Group. ${ }^{4}$ The pEP4EO2SEN2K plasmid contains the coding sequence of Oct-4, Sox-2, Nanog, and Klf-4, the $\mathrm{pEP} 4 \mathrm{EO} 2 \mathrm{SET} 2 \mathrm{~K}$ plasmid contains the coding sequence of Oct-4, Sox-2, SV40-T, and Klf-4, and the pCEP4-M2L plasmid contains the coding sequence of c-Myc and Lin28. The bacterial stabs of the three episomal plasmids were purchased from Addgene and the plasmids were amplified by Aldevron (Fargo, ND, USA). The three plasmids were used at a stoichiometric ratio of 3:3:2 and are referred to hereafter as the $\mathrm{T} 3$ plasmid combination.

\section{Biodegradable PBAE nanoparticles for nonviral gene delivery}

The acrylate monomers $(\mathrm{Bx})$, amino-alcohol monomers (Sy), and end-capping groups (Ez) used for polymer synthesis are shown in Figure 1. The number " $x$ " following the acrylate monomers " $\mathrm{B}$ " refers to the number of carbons between acrylate groups in the monomer, the number " $y$ " following the amino-alcohol monomers " $\mathrm{S}$ " refers to the number of carbons between the amine group and the alcohol group in the sidechain, and the number " $z$ " following the end-capping groups " $E$ " refers to an arbitrary number used to designate a particular end-capping group. A PBAE library was synthesized using a two-step procedure (Figure 1) as we have recently described. ${ }^{21,23-25}$ Briefly, acrylate-terminated polymers were first synthesized at different acrylate $(\mathrm{Bx})$ to amine $(\mathrm{Sy})$ monomer molar ratios $(1: 1,1.05: 1,1.1: 1$, and $1.2: 1)$ by conjugate addition for 48 hours at $40^{\circ} \mathrm{C}$ or for 24 hours at $90^{\circ} \mathrm{C}$. As a second step, amine-containing small molecules $(\mathrm{Ez})$ were individually conjugated to the ends of each base polymer (BxSy) to obtain the end-capped versions (BxSyEz). The final polymer stock solutions were stored in dimethyl sulfoxide at $100 \mathrm{mg} / \mathrm{mL}$ with desiccant at $4{ }^{\circ} \mathrm{C}$.

The top-performing polymer, ie, 1-(3-aminopropyl)-4methylpiperazine end-terminated poly (1,4-butanediol diacrylate-co-4-amino-1-butanol)(B4S4E7), from the PBAE library was synthesized in a large batch to avoid batch-to-batch variation in synthesis and ether-purified to remove any residual monomers by slight modification of the synthesis procedure. Five grams of the base polymer (B4S4) were synthesized at a molar ratio of 1.2:1 as described above. Five grams of B4S4 were then dissolved in $30 \mathrm{~mL}$ of tetrahydrofuran. A 1 $\mathrm{M}$ solution of E7 amine end-capping group was prepared in $10 \mathrm{~mL}$ of tetrahydrofuran and this amine solution was added to the base polymer solution. After stirring the solution at room temperature in the dark for 24 hours, the end-capped polymer (B4S4E7) was washed twice with anhydrous ethyl ether and dried in a desiccator connected to vacuum for 2 days. The polymer was dissolved in dimethyl sulfoxide at $100 \mathrm{mg} / \mathrm{mL}$ to form the polymer stock solution. The stock solution was stored at $-20^{\circ} \mathrm{C}$ in $1 \mathrm{~mL}$ aliquots. The molecular weight of the PBAEs was analyzed using gel permeation chromatography (Waters, Milford, MA, USA).

Polymer stock solutions and DNA stock solutions $(1 \mathrm{mg} / \mathrm{mL}$ in deionized water) were separately diluted in 


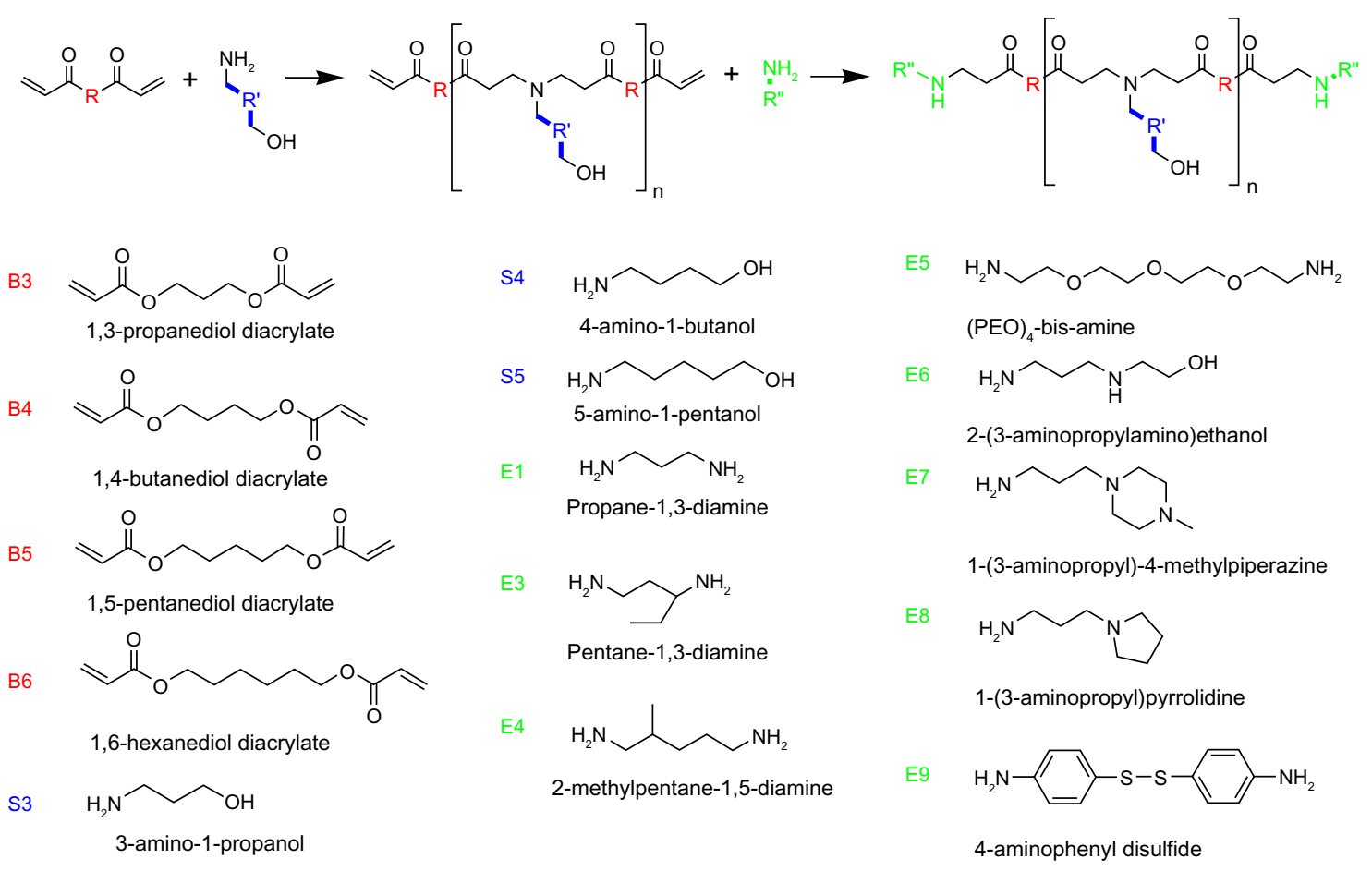

Figure I PBAE synthesis scheme and structure of monomers used for synthesis.

Notes: Acrylate monomers (Bx), amino-alcohol monomers (Sy), and end-capping groups (Ez). The number " $x$ " following the acrylate monomers "B" refers to the number of carbons between acrylate groups in the monomer, the number " $y$ " following the amino-alcohol monomers " $\mathrm{S}$ " refers to the number of carbons between the amine group and the alcohol group in the sidechain, and the number " $z$ " following the end-capping groups "E" refers to an arbitrary number used to designate a particular end-capping group. Abbreviation: PBAE, poly(beta-amino ester).

sodium acetate (NaAc) buffer ( $25 \mathrm{mM}, \mathrm{pH} 5)$ to concentrations required to synthesize particles at different polymer to DNA weight ratio (wt/wt). The two solutions were mixed by vortexing and particles formed by self-assembly.

\section{Cell transfection assay}

The library of PBAE polymers was screened for nonviral gene delivery in IMR-90 fibroblasts using a high-throughput 96-well transfection assay as described previously using

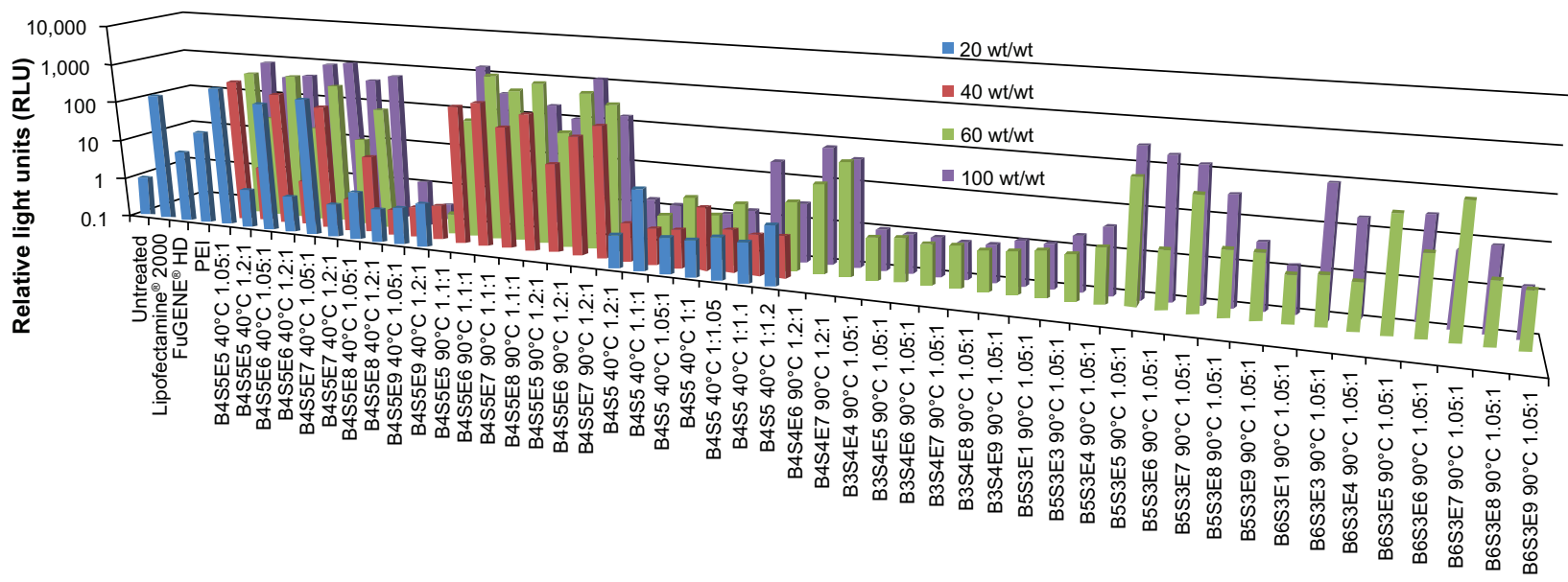

Figure 2 High-throughput screening data for gene delivery efficacy of PBAE polymers to IMR 90 cells. Luciferase-encoding DNA is delivered and expression is measured as RLU. Ratios I.05:I, I.I:I, I.2:I, I:I, and I:I.05 refer to polymerization conditions and wt/wt is the weight ratio of polymer to DNA. Graphs show the mean, $\mathrm{n} \geq 4$.

Notes: Acrylate monomers (Bx), amino-alcohol monomers (Sy), and end-capping groups (Ez). The number " $x$ " following the acrylate monomers "B" refers to the number of carbons between acrylate groups in the monomer, the number " $y$ " following the amino-alcohol monomers " $\mathrm{S}$ " refers to the number of carbons between the amine group and the alcohol group in the sidechain, and the number " $z$ " following the end-capping groups "E" refers to an arbitrary number used to designate a particular end-capping group. Abbreviations: PBAE, poly(beta-amino ester); RLU, relative light units; PEI, polyethylenimine. 
CMV-Luc reporter plasmid. ${ }^{26}$ FuGENE HD, Lipofectamine 2000 , and $25 \mathrm{kDa}$ polyethylenimine were used as controls according to the manufacturer's protocol. Forty-eight hours post-transfection, gene expression was measured using the
Bright-Glo luminescence assay (Promega, Madison, WI, USA) and a Synergy 2 (Bio-Tek, Winooski, VT, USA) multiplate reader (Figure 2). The top performing polymers were further optimized using EGFP-N1 reporter plasmid in

A
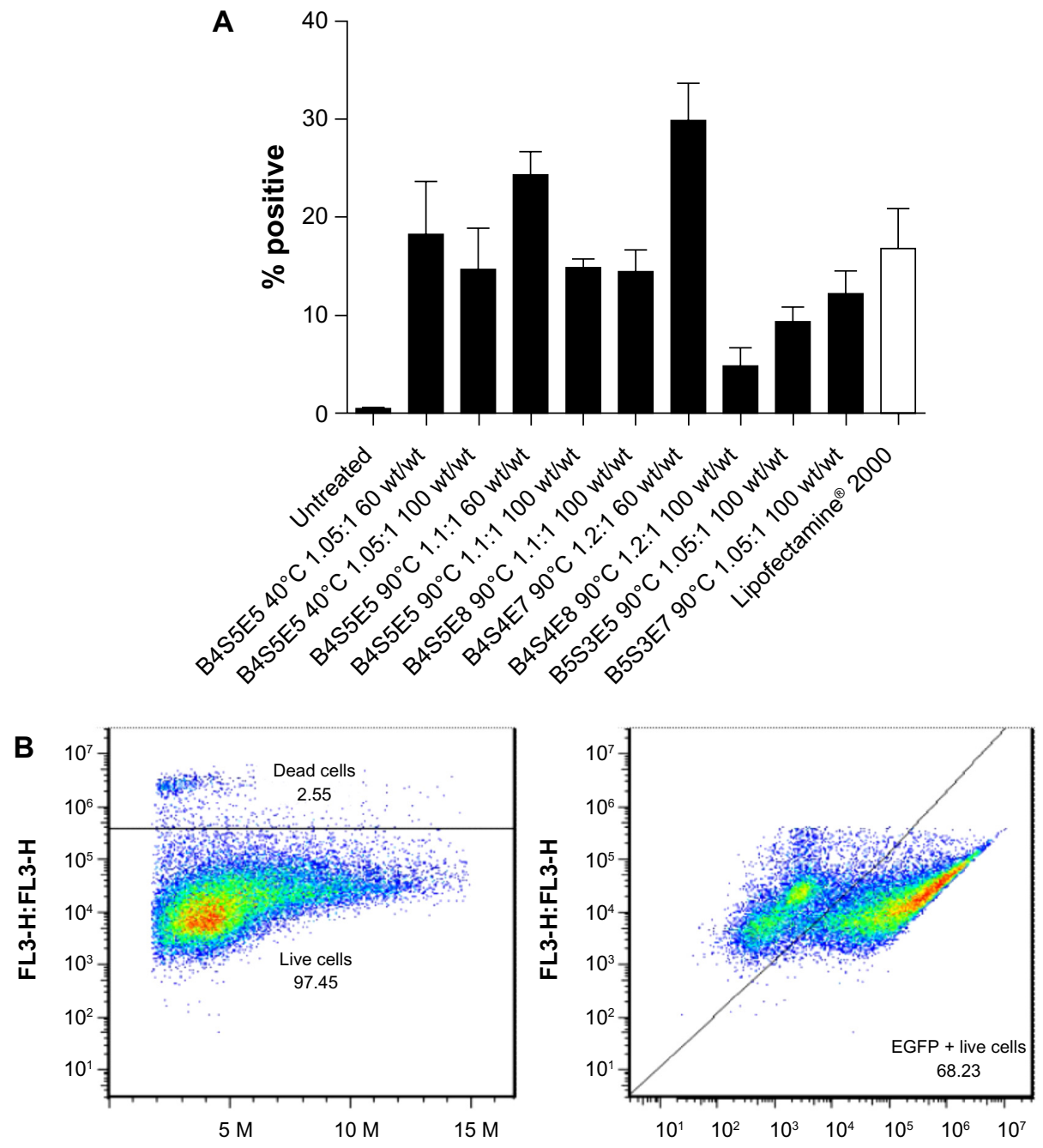

C
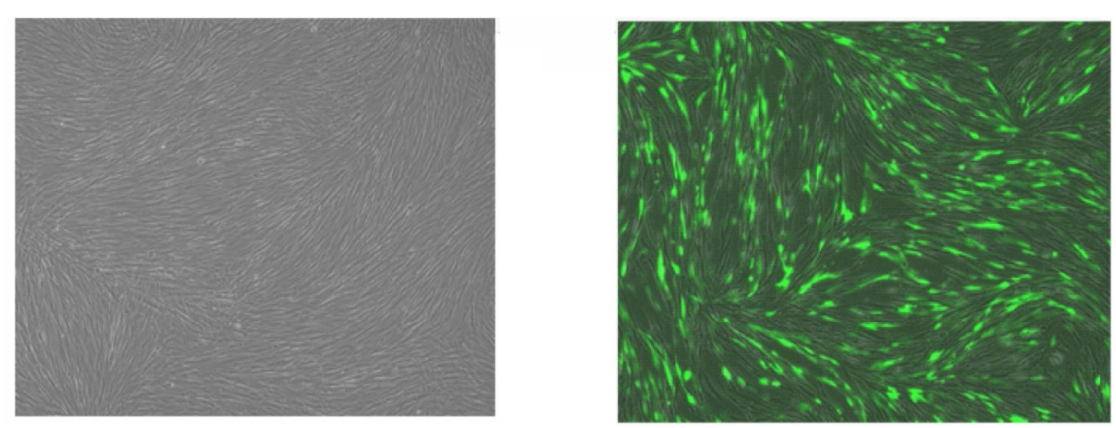

Figure 3 Flow cytometry data for IMR-90 cells transfected with EGFP using the leading polymers. Transfection efficacy expressed as percent green fluorescent proteinpositive live cells (A) following a single dose and (B) after three doses of B4S4E7 (68\%). Graphs show the mean \pm standard error of the mean, $n \geq 5$. (C) Fluorescence microscopy images of untreated (left) and transfected (right) IMR-90 fibroblasts, showing good viability in both cases.

Notes: Acrylate monomers (Bx), amino-alcohol monomers (Sy), and end-capping groups (Ez). The number " $x$ " following the acrylate monomers " $B$ " refers to the number of carbons between acrylate groups in the monomer, the number " $y$ " following the amino-alcohol monomers " $\mathrm{S}$ " refers to the number of carbons between the amine group and the alcohol group in the sidechain, and the number "z" following the end-capping groups "E" refers to an arbitrary number used to designate a particular end-capping group. Abbreviation: EGFP, enhanced green fluorescent protein. 


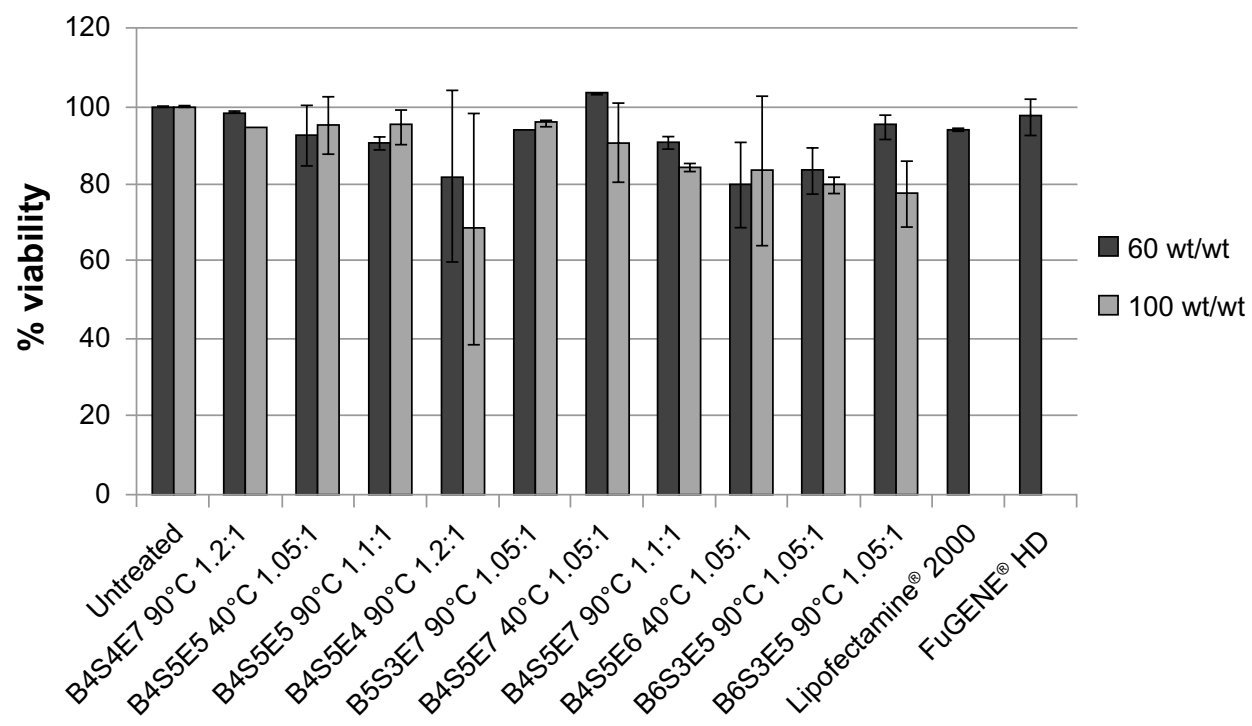

Figure 4 Cell viability data for IMR-90 cells transfected with EGFP/PBAE nanoparticles. Graphs show the mean \pm standard error of the mean, $n \geq 3$.

Notes: Acrylate monomers (Bx), amino-alcohol monomers (Sy), and end-capping groups (Ez). The number " $\mathrm{x}$ " following the acrylate monomers "B" refers to the number of carbons between acrylate groups in the monomer, the number " $y$ " following the amino-alcohol monomers " $\mathrm{S}$ " refers to the number of carbons between the amine group and the alcohol group in the sidechain, and the number " $z$ " following the end-capping groups "E" refers to an arbitrary number used to designate a particular end-capping group. Abbreviations: EGFP, enhanced green fluorescent protein; PBAE, poly(beta-amino ester).

scaled-up 24-well and six-well protocols, and transfection efficacy was analyzed using flow cytometry and fluorescence microscopy 48 hours post-transfection (Figure 3). The percent viability of the top performing polymers was determined using the CellTiter 96 AQueous One Solution Cell Proliferation Assay (Promega, Figure 4). The particle size of the top performing polymer was analyzed with nanoparticle tracking analysis using a NanoSight LM10-HS
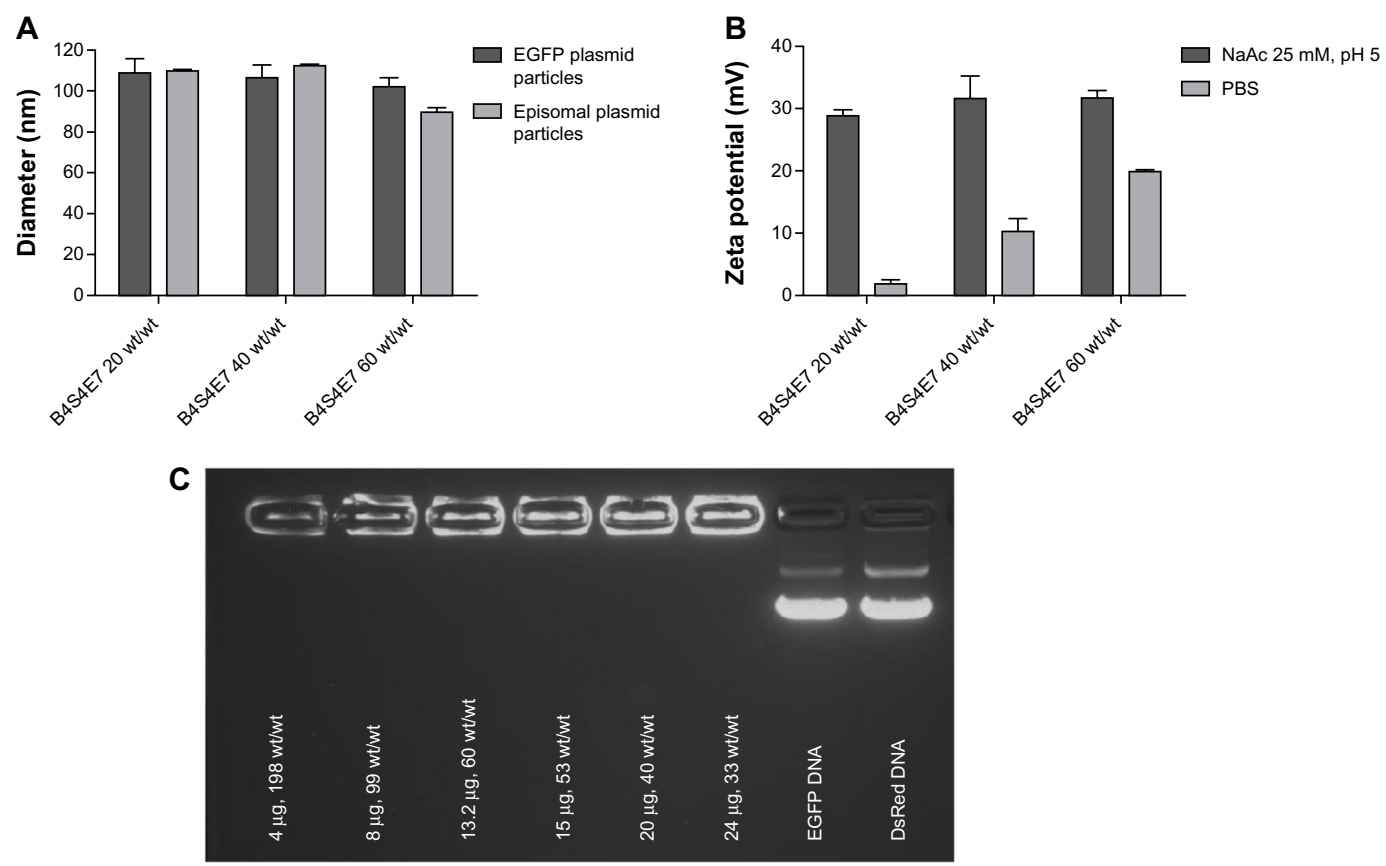

Figure 5 (A) Particle sizing data for PBAE nanoparticles complexed with EGFP plasmid ( $\sim \mathrm{kb})$ and episomal plasmid ( $16 \mathrm{~kb})$. Graph shows the mean \pm standard error of the mean, $n \geq 3$. (B) Zeta potential data for EGFP/B4S4E7 nanoparticles. Graphs show the mean \pm standard error of the mean, $n=5$. (C) Gel retardation assay data for EGFP/ B4S4E7 nanoparticles.

Notes: Acrylate monomers (Bx), amino-alcohol monomers (Sy), and end-capping groups (Ez). The number " $x$ " following the acrylate monomers "B" refers to the number of carbons between acrylate groups in the monomer, the number " $y$ " following the amino-alcohol monomers " $\mathrm{S}$ " refers to the number of carbons between the amine group and the alcohol group in the sidechain, and the number " $z$ " following the end-capping groups "E" refers to an arbitrary number used to designate a particular end-capping group. Abbreviations: EGFP, enhanced green fluorescent protein; PBAE, poly(beta-amino ester); PBS, phosphate buffered saline; NaAc, sodium acetate. 


\section{A}

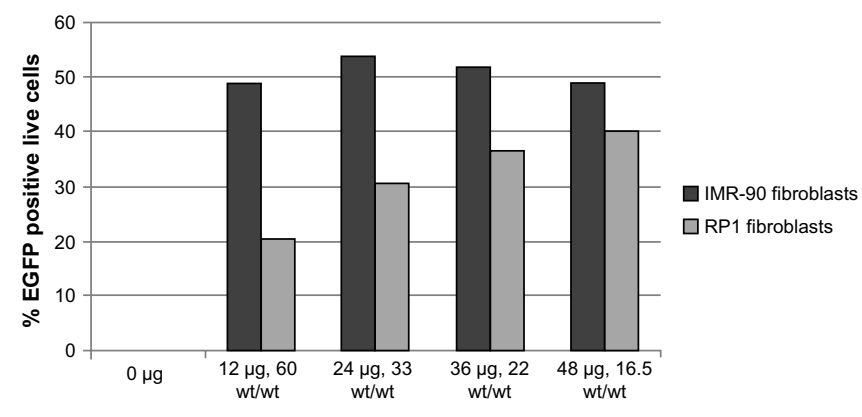

B

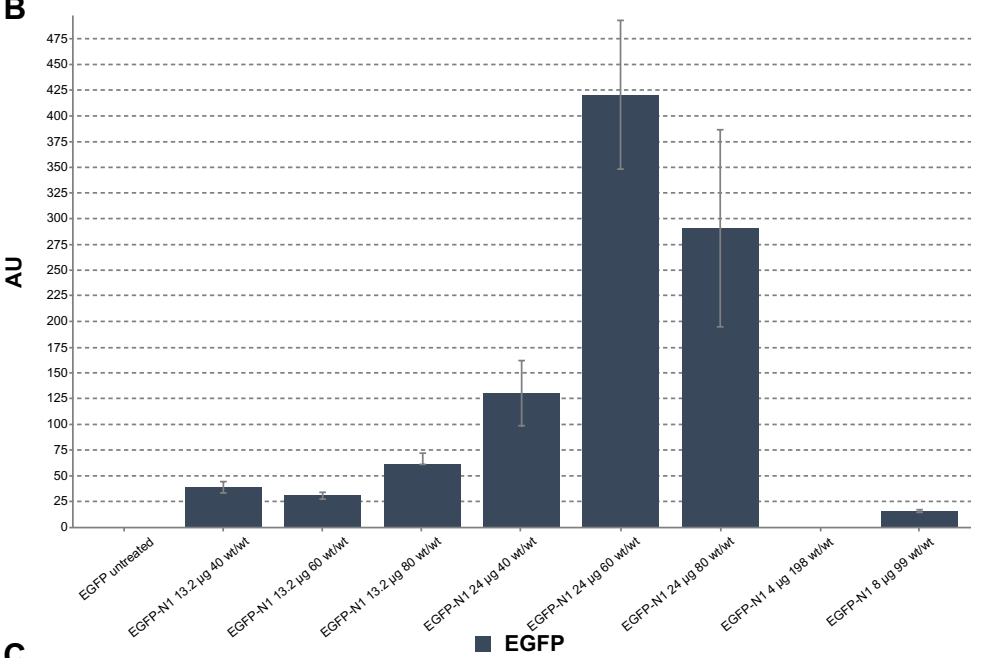

C

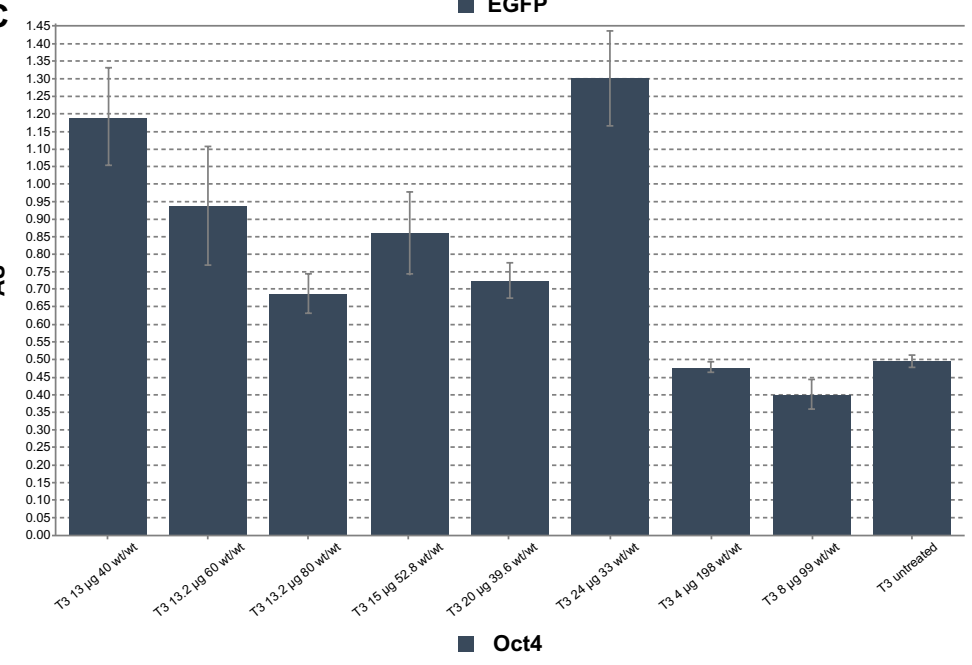

Figure 6 (A) Dose response curve for fibroblasts transfected with EGFP/B4S4E7 nanoparticles. (B) qPCR analysis data showing EGFP messenger (m)RNA expression levels in RP patient-specific adult dermal fibroblasts transfected with B4S4E7/EGFP nanoparticles. Graph shows the mean \pm standard deviation, $n=3$. (C) qPCR analysis data showing Oct4 mRNA expression levels in RP patient-specific adult dermal fibroblasts transfected with B4S4E7/T3 nanoparticles. Graph shows the mean \pm standard deviation, $\mathrm{n}=3$.

Notes: Acrylate monomers ( $\mathrm{Bx}$ ), amino-alcohol monomers (Sy), and end-capping groups (Ez). The number " $\mathrm{x}$ " following the acrylate monomers "B" refers to the number of carbons between acrylate groups in the monomer, the number " $y$ " following the amino-alcohol monomers " $\mathrm{S}$ " refers to the number of carbons between the amine group and the alcohol group in the sidechain, and the number " $z$ " following the end-capping groups "E" refers to an arbitrary number used to designate a particular end-capping group.

Abbreviations: EGFP, enhanced green fluorescent protein; qPCR, quantitative polymerase chain reaction; RP, retinitis pigmentosa; T3, three reprogramming plasmids.

(NanoSight, Salisbury, UK) and the zeta potential was analyzed by dynamic light scattering using a Zetasizer NanoZS (Malvern Instruments, Malvern, UK; Figure 5). The transfection conditions were optimized for high efficacy and low cytotoxicity by tuning the polymer/DNA wt/wt, nanoparticle incubation time, and DNA dose per well using flow cytometry and quantitative polymerase chain reaction (qPCR) analysis (Figure 6). 

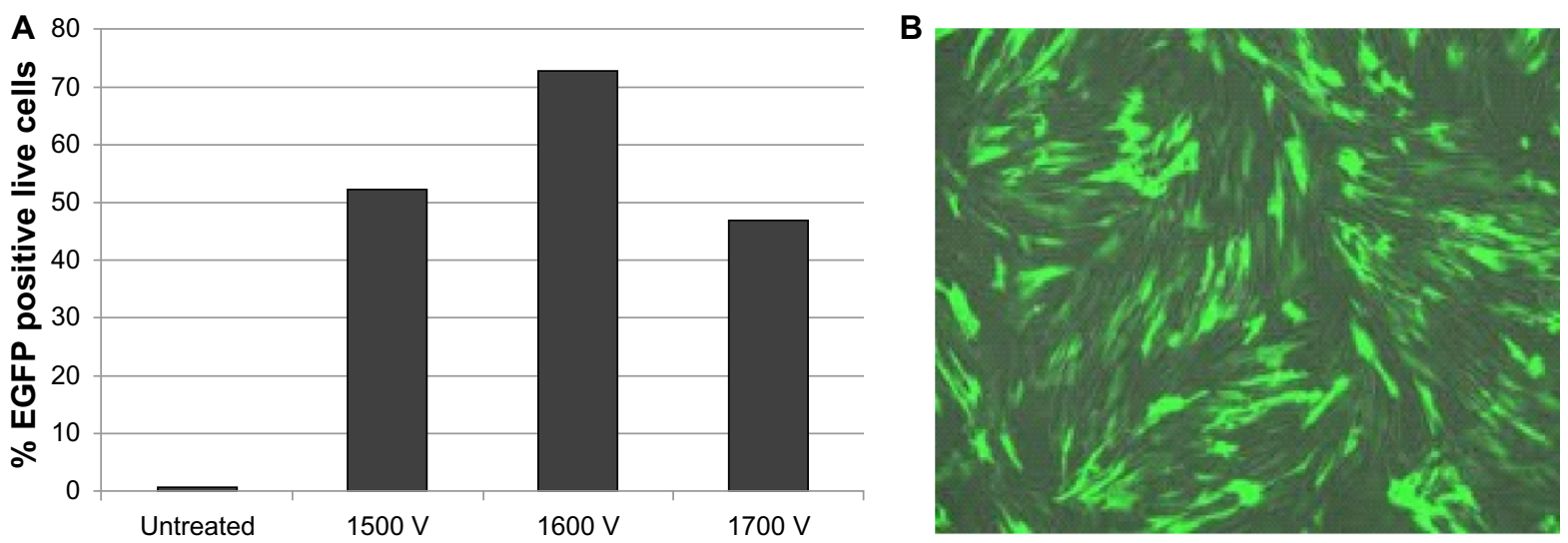

Figure 7 (A) Flow cytometry data for IMR-90 cells electroporated with EGFP-NI plasmid at different voltages, ie, I,500 V, I,600 V, and I,700 V. (B) Fluorescence microscopy image of IMR-90 cells electroporated with EGFP-NI plasmid at I,500 V.

Abbreviation: EGFP, enhanced green fluorescent protein.

\section{Nonviral gene delivery by electroporation}

One million IMR-90 fibroblast cells were electroporated using a $100 \mu \mathrm{L}$ tip-type in a $\mathrm{Neon}^{\circledR}$ transfection system and MP-100 microporator (Life Technologies, Figure 7). Total plasmid DNA (EGFP-N1 reporter plasmid or T3 reprogramming plasmids) was used at $10-12 \mu \mathrm{g}$ per electroporation experiment. The parameters used for electroporation were optimized for IMR-90 fibroblasts, and the final settings used were: pulse voltage $1,500 \mathrm{~V}$, pulse length, $30 \mathrm{msec}$, and pulse number 1 .

Specifically, IMR-90s were trypsinized for 3 minutes with $1 \times$ TrypLE or $0.05 \%$ trypsin-ethylenediaminetetraacetic acid (Life Technologies) and neutralized with fibroblast culture medium. The cells were spun at $80 \times \mathrm{g}$ for 5 minutes at room temperature and resuspended in $4 \mathrm{~mL}$ of fibroblast culture medium. The cells were then counted and the cell solution corresponding to one million cells was transferred to a microcentrifuge tube, and the cells were spun at $50 \times \mathrm{g}$ for 5 minutes in a table-top microcentrifuge. The cells were resuspended in $112 \mu \mathrm{L}$ of solution consisting of $100 \mu \mathrm{L}$ of electroporation buffer R and $12 \mu \mathrm{L}$ of T3 plasmids. The MP-100 microporator parameters were set for IMR-90 fibroblasts, and a $15 \mathrm{~mL}$ centrifuge tube was filled with $8 \mathrm{~mL}$ of fibroblast culture medium. The cell suspension was pipetted up and down with a p100 pipette tip and carefully transferred to a $100 \mu \mathrm{L}$ microporator tip while avoiding any bubbles. The microporator tip, which acts as a transfection chamber, was immersed in electrolytic buffer E2, and the cells were electroporated and added to a $15 \mathrm{~mL}$ conical tube containing $8 \mathrm{~mL}$ of fibroblast culture medium. The cells were mixed gently and the total cell suspension was transferred into four wells of a six-well plate to achieve a plating density of about 250,000 cells per well.

\section{Nonviral feeder-independent reprogramming strategy}

PBAE nanoparticle-based reprogramming

The PBAE nanoparticle-based reprogramming strategy is summarized in Figure 8A. The detailed protocol is as follows.

Day 0: early passage $(<\mathrm{p} 8)$ IMR-90 fibroblasts were plated at a density of 180,000-250,000 cells/well in a sixwell tissue culture-treated plate. Cells were maintained at $37^{\circ} \mathrm{C}, 21 \% \mathrm{O}_{2}$, and $5 \% \mathrm{CO}_{2}$ (normoxia conditions) in human fibroblast culture medium.

Day 1: two wells with a cell density of 250,000 cells/well were transfected per nanoparticle formulation. Cells were transfected with $15 \mu \mathrm{g}$ of T3 plasmid combination per well using B4S4E7 1.2:1 $90^{\circ} \mathrm{C}$ polymer complexed at a polymer to DNA weight ratio of $60 \mathrm{wt} / \mathrm{wt}$. Cells were incubated with nanoparticles for 4 hours at normoxia conditions in human fibroblast culture medium. Fresh human fibroblast medium was added after the incubation period and cells were maintained at normoxia conditions.

Day 2: cells were transferred to $37^{\circ} \mathrm{C}, 3 \% \mathrm{O}_{2}$, and $10 \% \mathrm{CO}_{2}$ (hypoxia conditions) and maintained in mTeSR1 medium supplemented with $20-50 \mathrm{ng} / \mathrm{mL}$ basic fibroblast growth factor and a cocktail of small molecules consisting of $0.25 \mathrm{mM}$ sodium butyrate and $5 \mu \mathrm{M}$ PS48. Cells were maintained in this reprogramming medium until day 11 .

Day 3: cells were transfected with the same conditions of PBAE nanoparticles and the T3 plasmid combination as on day 1 , except in mTeSR1 reprogramming medium.

Day 4: cells were passaged using $0.05 \%$ trypsinethylenediaminetetraacetic acid and transferred to a Matrigelcoated six-well plate at 150,000 cells/well. 
A

MEM mTeSR1 (supplemented

$10 \%$ with $20 \mathrm{ng} / \mathrm{mL}$ bFGF, 0.25

FBS $\quad \mathrm{mM} \mathrm{NaB}, 5 \mu \mathrm{M}$ PS48)

mTeSR1 (supplemented with $20 \mathrm{ng} / \mathrm{mL}$ bFGF)

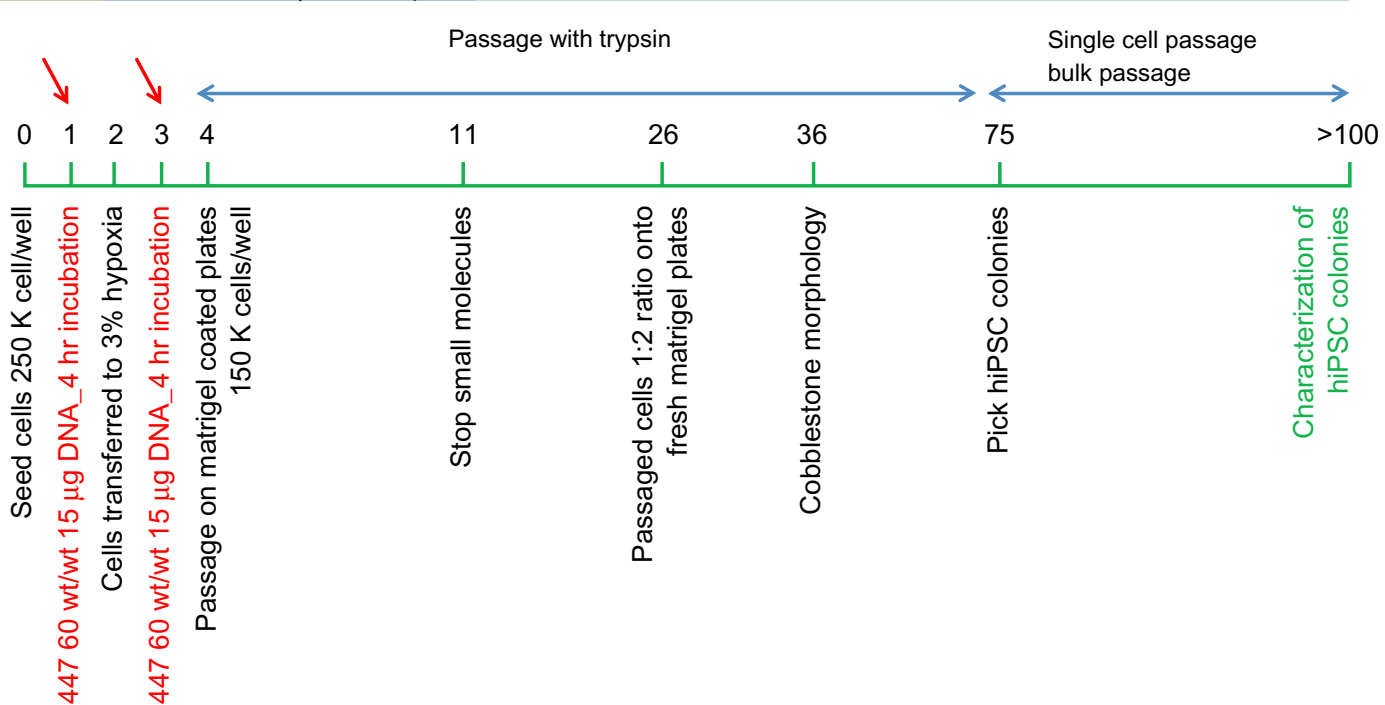

B

$\begin{array}{cc}\text { MEM } & \text { mTeSR1 (supplemented } \\ 10 \% & \text { with } 20 \mathrm{ng} / \mathrm{mL} \text { bFGF, } 0.25\end{array}$

FBS $\quad \mathrm{mM} \mathrm{NaB}, 5 \mu \mathrm{M}$ PS48)

mTeSR1 (supplemented with $20 \mathrm{ng} / \mathrm{mL}$ bFGF)

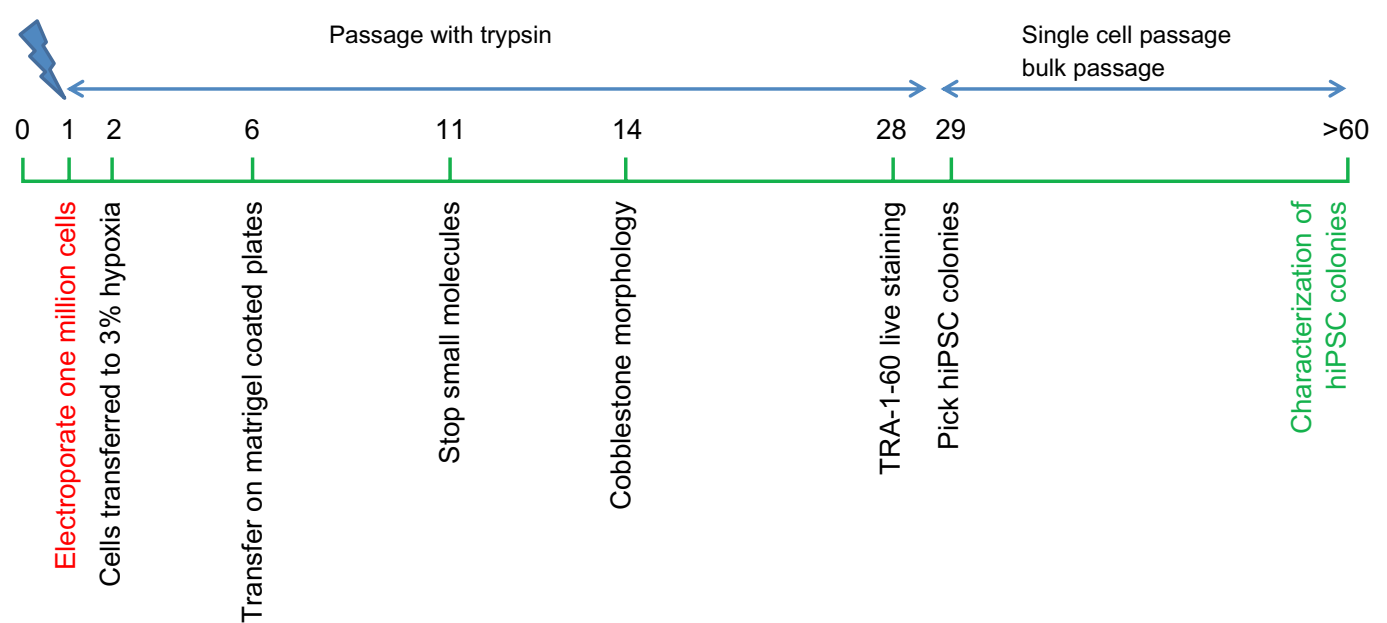

Figure 8 (A) PBAE-nanoparticle based feeder-independent reprogramming strategy. (B) Electroporation based feeder-independent reprogramming strategy. Notes: The green bar represents days. Red arrows show the day of polymer-based transfection; blue arrows show the day of electroporation.

Abbreviations: PBAE, poly(beta-amino ester); MEM, minimum essential medium; FBS, fetal bovine serum; bFGF, basic fibroblast growth factor; hiPSC, human induced pluripotent stem cell; $\mathrm{NaB}$, sodium butyrate.

Day 11: small molecules were withdrawn from the reprogramming medium. Cells were now maintained in mTeSR1 medium supplemented with $20 \mathrm{ng} / \mathrm{mL}$ basic fibroblast growth factor.

Days 25-30: cells were passaged using trypsin and transferred at a 1:2 ratio to fresh Matrigel plates.

Day 36: first signs of embryonic stem cell-like morphologic changes were observed.

Day 75: small human iPSC-like colonies were visualized and referred to as EP2 lines. Thirteen iPSC-like colonies were manually isolated from a starting population of 500,000 cells and gently transferred to a new dish. The two most promising representative colonies (EP2.1 and EP2.2) were propagated further using a single-cell passaging approach with Accutase and blebbistatin and characterized by karyotyping, immunostaining, and differentiation.

Day $>100$ : characterization of the pluripotency potential of the nonvirally derived human iPSC-like colonies by Tra-1-60 live staining (Millipore, Billerica, MA, USA), immunocytochemistry, karyotyping, and in vitro differentiation. 


\section{Electroporation-based reprogramming strategy}

The electroporation-based reprogramming strategy is summarized in Figure 8B. The protocol used was as follows.

Day 0: early passage $(<\mathrm{p} 8)$ IMR-90 fibroblasts were grown on a Matrigel-coated $T 175 \mathrm{~cm}^{2}$ cell culture flask at $37^{\circ} \mathrm{C}, 21 \% \mathrm{O}_{2}$, and $5 \% \mathrm{CO}_{2}$ (normoxia conditions) in human fibroblast culture medium.

Day 1: cells were trypsinized and one million cells were electroporated with $12 \mu \mathrm{g}$ of T3 plasmid combination as described earlier. Cells were plated at a density of 200,000-250,000 cells/well in six wells of a six-well plate in fresh human fibroblast medium and maintained at normoxia conditions.

Day 2: the cells were transferred to $37^{\circ} \mathrm{C}, 3 \% \mathrm{O}_{2}$, and $10 \%$ $\mathrm{CO}_{2}$ (hypoxia conditions) and maintained in mTeSR 1 medium supplemented with $20-50 \mathrm{ng} / \mathrm{mL}$ basic fibroblast growth factor and a cocktail of small molecules consisting of $0.25 \mathrm{mM}$ sodium butyrate and $5 \mu \mathrm{M}$ PS48. Cells were maintained in this reprogramming medium until day 11 .

Day 6: cells were passaged using $0.05 \%$ trypsin-ethylenediaminetetraacetic acid and transferred to a fresh Matrigelcoated six-well plate at 150,000 cells/well.

Day 11: small molecules were withdrawn from the reprogramming medium. Cells were now maintained in mTeSR1 medium supplemented with $20 \mathrm{ng} / \mathrm{mL}$ basic fibroblast growth factor.

Day 14: first signs of embryonic stem cell-like cobblestone morphologic changes were observed.

Days 25-30: cells were stained using a Tra-1-60 live staining protocol. Tra-1-60-positive human iPSC-like colonies were picked for propagation and referred to as EP1 lines.

Days 30-60: eleven human iPSC-like colonies were manually selected by gently transferring individual colonies to separate dishes. One representative colony (EP1.1) was propagated further using a single-cell passaging approach with Accutase and blebbistatin at a density of $10-20,000$ cells/well in a $35 \mathrm{~mm}$ dish.

Day $>60$ : characterization of the pluripotency potential of the nonvirally derived human iPSC-like cells was accomplished by immunostaining, karyotyping, and in vitro differentiation to neuronal lineage.

\section{Mechanical isolation of human iPSC-like colonies}

Early-passage human iPSC-like colonies were mechanically isolated when they reached a size just smaller than one field of a $10 \times$ objective (about 1,000 $\mu \mathrm{m}$ ). Reduced growth factor Matrigel-coated plates were prepared 8-30 hours before passaging. A finely drawn out glass Pasteur pipette was used to dissect the colonies into four quarters and each quarter was gently lifted with a p200 pipette tip and transferred to a Matrigel-coated well filled with mTeSR1 medium.

\section{Single-cell passage of human iPSC-like colonies}

Late-passage human iPSC-like colonies were single-cell passaged when they reached a size just smaller than one field

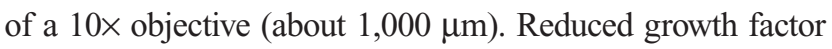
Matrigel-coated plates were prepared 8-30 hours prior to passaging. One milligram of blebbistatin was dissolved in $340 \mu \mathrm{L}$ of dimethyl sulfoxide to make a $10 \mathrm{mM}(2,000 \times)$ stock solution, and $10 \mu \mathrm{L}$ aliquots of this solution were stored at $-80^{\circ} \mathrm{C}$ protected from light. For each experiment, $10 \mu \mathrm{L}$ of the blebbistatin stock solution was added to each $20 \mathrm{~mL}$ of mTeSR1 to make a fresh single-use working medium. The cells were pretreated for 10 minutes with $5 \mu \mathrm{M}$ blebbistatin in mTeSR 1 and then treated with $1 \mathrm{~mL}$ of prewarmed Accutase per $35 \mathrm{~mm}$ dish for 5-7 minutes. Cells were dissociated by gentle trituration, quenched with $2 \mathrm{~mL}$ of mTeSR1, and pelleted at $80 \times \mathrm{g}$ for 5 minutes at room temperature. Cells were resuspended in $1 \mathrm{~mL}$ of mTeSR 1 with blebbistatin at a density of 10,000-20,000 cells per $35 \mathrm{~mm}$ dish or per well of a six-well plate. The media was switched to mTeSR1 without blebbistatin 48 hours after passaging.

\section{Immunostaining}

After 5 minutes of fixation in 4\% paraformaldehyde in phosphate-buffered saline containing 5\% sucrose, the cells were blocked and permeabilized for 30 minutes in $2 \%$ normal donkey serum, $0.1 \%$ Triton X-100 in phosphate-buffered saline, and then incubated overnight at $4{ }^{\circ} \mathrm{C}$ with the following antibodies: rabbit anti-Oct4 1/500 (Abcam Inc, Cambridge, MA, USA), rabbit anti-Nanog 1/1000 (Millipore), rabbit anti-Sox2 1/1000 (Millipore), mouse anti-SSEA4 1/100 (Millipore), rabbit polyclonal anti-Pax6 (Covance, Princeton, NJ, USA), and mouse monoclonal anti-Tuj1 1/1000 (Covance). After three rinses in phosphatebuffered saline, the cells were incubated for 1 hour with the corresponding secondary antibody conjugated to Alexa-488 or Alexa-647 (Invitrogen), and counterstained with the nuclear dye Hoechst 33342 (Invitrogen).

\section{Karyotype analysis}

The human iPSC-like colonies were karyotyped at Cell Line Genetics (Madison, WI, USA). The EP1 line was karyotyped at passage number 14, and the EP2.1 and EP2.2 lines were both karyotyped at passage number 16 . 


\section{In vitro neural differentiation assay}

iPSC-like cells maintained in mTeSR 1 were incubated for $5 \mathrm{~min}$ utes in $1 \mathrm{mg} / \mathrm{mL}$ dispase and clump-passaged to form embryoid bodies according to a modified serum or knockout serum replacement-free protocol adapted from Meyer et al. ${ }^{27}$ Briefly, over a 4-day period, the embryoid bodies were transitioned from mTeSR1 to neural induction medium comprised of DMEM:F12 (1:1) containing $2 \mathrm{mM}$ glutamine, $1 \% \mathrm{~N} 2$ supplement, $1 \times$ nonessential amino acids, and heparin sulfate. At day 5, the embryoid bodies were plated onto dishes coated with reduced growth factor Matrigel to allow for neural rosette formation and further cultured in nonessential medium until day 13 , at which time rosettes were mechanically lifted from the plate by passing a strong stream of medium over the neural rosettes which preferentially lifted off the plate. Neurospheres were grown at low density as floating spheres on uncoated polystyrene dishes for several weeks, at which time cultures were enzymatically dissociated into small clumps and single cells, and reattached onto Matrigel-coated dishes.

\section{qPCR analysis}

EGFP and Oct4 expression was quantified by qPCR analysis in dermal fibroblasts derived from a patient with retinitis pigmentosa post-transfection with varying conditions of B4S4E7/ EGFP-N1 nanoparticles and B4S4E7/T3 nanoparticles, respectively. The transfection conditions were optimized by varying the DNA dose and polymer to DNA weight ratio (wt/ wt). The mRNA was isolated from the cells using RNeasy Mini Kit (Qiagen, Venlo, The Netherlands). Oct4 primers used were hOct4(120) forward ATTCTCCAGGTTGCCTCTCA and hOct4(120) reverse GTGGAGGAAGCTGACAACAA. EGFP primers used were EGFP(235) for CACATGAAGCAGCACGACTT and EGFP(235) reverse CGGCCATGATATAGACGTTG. Three housekeeping genes were used: $C R E B-B P$ (CREBBP forward GAGAGCAAGCAAACGGAGAG and $C R E B B P$ reverse AAGGGAGGCAAACAGGACA), SRP72 (SRP72 forward TCTGCCTCTACAAGTAACATCAT and SRP72 reverse CTCATCACCAGCCACCTT) and $F B X 12$ ( $F B X 12$ forward GCCTTGGTCATATCATCAG and $F B X 12$ reverse TTCTTCATCCGTCCTGTT) ${ }^{28}$ The qPCR analysis was done on a BioRad PCR station (BioRad, Hercules, CA, USA) and the qPCR data were analyzed using qbase PLUS software (Biogazelle, Zwijnaarde, Belgium).

\section{Results and discussion Biodegradable PBAE nanoparticles for nonviral gene delivery to fibroblasts}

A library of cationic biodegradable PBAEs useful for nonviral gene delivery to hard-to-transfect human fibroblasts was developed. The polymers were synthesized via a Michael addition reaction by using various combinations of the diacrylate (Bx), amino-alcohol (Sy) and end-capping group (Ez) monomers shown in Figure 1. In addition to varying the polymer backbone chemical structure, the synthesis conditions were also varied, including temperature $\left(40^{\circ} \mathrm{C}\right.$ versus $90^{\circ} \mathrm{C}$ ) and diacrylate to amine monomer ratio, to expand the structures in the library. Upon electrostatic self-complexation with the reporter plasmids CMV-Luc and EGFP-N1, the PBAEs formed gene delivery nanoparticles with particle diameters of approximately $100 \mathrm{~nm}$ (Figure 5A). Using the particle size distribution data from nanoparticle tracking analysis measurements, the number of plasmids associated with a single PBAE-based nanoparticle was quantified. ${ }^{21}$ It was observed that 30-100 plasmids were encapsulated in each nanoparticle depending on polymer structure.

To identify polymers from the PBAE library with the ability to transfect human fibroblasts in an efficacious, rapid, and high-throughput manner, the PBAE library was screened on IMR-90 fetal lung fibroblasts using a 96-well plate assay. ${ }^{26}$ PBAE/CMV-Luc nanoparticles were synthesized by varying the polymer to DNA weight ratio from $20 \mathrm{wt} / \mathrm{wt}$ to $100 \mathrm{wt} / \mathrm{wt}$. Figure 2 shows the compiled transfection efficacy data reported as relative luminescence units per well. Several PBAE nanoparticle conditions had higher transfection efficacy than the commercial controls, ie, FuGENE HD, Lipofectamine 2000, and polyethylenimine. In general, the transfection efficacy increased with increasing $\mathrm{wt} / \mathrm{wt}$ ratio $(20 \mathrm{wt} / \mathrm{wt}<100 \mathrm{wt} / \mathrm{wt})$ and with increasing synthesis temperature $\left(40^{\circ} \mathrm{C}<90^{\circ} \mathrm{C}\right)$. The top performing polymers, determined from the high-throughput 96-well plate screening, were further optimized using EGFP-N1 reporter plasmid in 24-well and six-well plate transfection assays, and their transfection efficacy was quantified using flow cytometry (Figure 3). The high performers included B4S5E5 1.05:1 $90^{\circ} \mathrm{C}$, B4S5E5 $1.1: 190^{\circ} \mathrm{C}, \mathrm{B} 4 \mathrm{~S} 5 \mathrm{E} 81.1: 190^{\circ} \mathrm{C}$, B4S4E7 1.2:1 $90^{\circ} \mathrm{C}$, B4S4E8 $1.2: 190^{\circ} \mathrm{C}$, B5S3E5 $1.05: 190^{\circ} \mathrm{C}$, and B5S3E7 1.05:1 $90^{\circ} \mathrm{C}$. Nanoparticles were formed at $60 \mathrm{wt} / \mathrm{wt}$. The mean transfection efficacy of the best performing polymer, B4S4E7 1.2:1 $90^{\circ} \mathrm{C}$, was $30 \% \pm 4 \%(n=8)$, which was about two-fold higher than the mean transfection efficacy of Lipofectamine 2000 , ie, $17 \% \pm 4 \%(n=10)$. Interestingly, the PBAE with the highest transfection efficacy, B4S4E7, had about 100 plasmids associated with a single nanoparticle as reported by Bhise et al, ${ }^{21}$ which is more than two-fold the number of plasmids per nanoparticle calculated for B5S3E7 1.05:1 $90^{\circ} \mathrm{C}$, a PBAE with low transfection efficacy of $12 \% \pm 4 \%(\mathrm{n}=10)$. Both of these PBAE structures have similar 
hydrophobicity and the same end-capping group consisting of tertiary amines, but have different transfection efficacies, which may be partly due to differences in their plasmids per particle counts. Due to the high amount of plasmids per particle, we have found that B4S4E7 is effective at coexpression of exogenously delivered genes as is needed for reprogramming. ${ }^{21}$

Figure $5 \mathrm{~B}$ shows the mean zeta potential $(\mathrm{mV})$ of B4S4E7/EGFP nanoparticles formed at 20,30, and $60 \mathrm{wt} / \mathrm{wt}$ in phosphate-buffered saline and NaAc buffers. For all three $\mathrm{wt} / \mathrm{wt}$ values, the mean zeta potential of B4S4E7 nanoparticles formulated in NaAc ( $25 \mathrm{mM}, \mathrm{pH}$ 5) buffer is greater than the mean zeta potential of B4S4E7 formulated in phosphatebuffered saline. For example, the mean zeta potential of 60 $\mathrm{wt} / \mathrm{wt}$ particles is $32 \pm 1 \mathrm{mV}(\mathrm{n}=5)$ in NaAc and $20 \pm 5 \mathrm{mV}$ $(n=5)$ in phosphate-buffered saline. The greater positive surface charge indicates that more amines in the PBAE backbone are positively charged in NaAc buffer at $\mathrm{pH} 5$ than in phosphate-buffered saline at $\mathrm{pH}$ 7. This increased cationic density allows PBAEs to better complex the negatively charged plasmids in NaAc buffer. The zeta potential of B4S4E7 nanoparticles in NaAc buffer is about $30 \mathrm{mV}$ for all three $\mathrm{wt} / \mathrm{wt}$ formulations, whereas in phosphate-buffered saline the mean zeta potential increased slightly with increasing $w t / w t$. The NaAc buffer maintains the stability of B4S4E7 nanoparticles even at a low wt/wt formulation $(20 \mathrm{wt} / \mathrm{wt})$. The stability of B4S4E7 nanoparticles was also tested using a gel retardation assay (Figure 5C).

The percent viability determined using the CellTiter cell proliferation assay for the top performing PBAE, B4S4E7, was $>90 \%$, demonstrating low cytotoxicity (Figure 4 ). The transfection efficacy of the best performing polymer, B4S4E7, after a single dose was further boosted by serially transfecting on alternate days for a total of three doses. The transfection efficacy after three doses with B4S4E7 was $68 \%$ on day 6 following the first transfection dose (Figure 3B). To maintain an appropriate confluency of cells for the third transfection dose, cells were passaged a day prior to the third transfection dose on day 3. Prolonging the expression of transfected factors is particularly important for successful reprogramming, since it is a gradual process that requires expression of reprogramming factors for a duration of $1-3$ weeks. ${ }^{29}$

A dose-response curve was generated to determine the optimal dose of EGFP-N1 DNA $(\mu \mathrm{g})$ per well of a six-well plate by varying the DNA dose per well from $12 \mu \mathrm{g}$ to $48 \mu \mathrm{g}$ while keeping a constant polymer amount $(792 \mu \mathrm{g} /$ well, Figure 6A). In the case of IMR-90 fetal fibroblasts, there was no significant increase in percent transfection efficacy as the dose was increased from $12 \mu \mathrm{g}$ to $48 \mu \mathrm{g}$. For the adult fibroblasts derived from a patient with retinitis pigmentosa, however, there was a general trend of increasing transfection efficacy with increasing DNA dose. In addition to the dose-dependent increase in the number of transfected cells per condition, there was a dose-dependent increase in the EGFP mRNA expression level in fibroblasts derived from a patient with retinitis pigmentosa, as quantified by $\mathrm{qPCR}$ analysis (Figure 6B).

\section{Nonviral feeder-independent reprogramming strategy}

The B4S4E7 polymer was used to deliver T3 episomal plasmids containing coding sequences for the reprogramming factors to IMR-90 cells in a six-well protocol. A combination of three episomal plasmids (T3) was used to deliver six factors (Oct4, Sox2, NANOG, LIN28, KLF4, and c-Myc). The nonviral reprogramming process, which was performed in a feeder-independent manner, was optimized by modifying the polymer/DNA weight ratio (wt/wt), dose of DNA per well, number of repeat transfections, timing of transfections, and density of cells. For consistency across reprogramming experiments, the top-performing polymer B4S4E7 was synthesized in large scale at $5 \mathrm{mg}$ and purified by precipitation. Particle size was determined using nanoparticle tracking analysis and a gel retardation assay ${ }^{21}$ was performed to verify effective complexation of the episomal plasmids, which were larger in size $(\sim 16 \mathrm{~kb})$ as compared with the reporter plasmids $(\sim 5 \mathrm{~kb})$. We formed $100 \mathrm{~nm}$ B4S4E7 particles with a $16 \mathrm{~kb}$ T3 episomal plasmid similar to the nanoparticles formed with the $5 \mathrm{~kb}$ reporter EGFP plasmid (Figure 5A). B4S4E7 nanoparticles can also be stored long-term using a freezedrying process that we have recently described. ${ }^{25}$

The ability of PBAE nanoparticles to deliver the episomal plasmids was verified by qPCR. Figure $6 \mathrm{C}$ shows $\mathrm{qPCR}$ data quantifying the expression levels of Oct4 mRNA from patient-derived fibroblasts transfected with the B4S4E7-based nanoparticles (DNA dose per well ranged from $4 \mu \mathrm{g}$ to $24 \mu \mathrm{g}$, and polymer to DNA wt/wt ratios ranged from 40 to $80 \mathrm{wt} /$ wt). In the case of Oct 4 expression, the $4 \mu \mathrm{g}$ and $8 \mu \mathrm{g}$ dose per well conditions did not show any increase in Oct4 levels over the untreated control condition. As the dose was increased beyond $8 \mu \mathrm{g}$, there was a detectable increase in Oct4 levels above the untreated control condition. Interestingly, for the $13.2 \mu \mathrm{g}$ per well condition, Oct 4 mRNA expression decreased with an increase in amount of polymer per well from $40 \mathrm{wt} /$ wt to $80 \mathrm{wt} / \mathrm{wt}$. This suggests that increasing the amount 
of polymer may have an inhibitory effect on T3 plasmid expression. We observed that the fibroblasts often appeared stressed, showing reduced proliferation in the wells treated with B4S4E7 amounts $>792 \mu \mathrm{g} /$ well. Thus, for B4S4E7/T3 transfections in a six-well plate format, the optimal amount of polymer per well was determined to be about $792 \mu \mathrm{g}$ and the optimal amount of DNA per well was determined to be $>13.2 \mu \mathrm{g}$ per well.

T3 episomal plasmids are well suited for transient exogenous expression due to their ability to self-replicate; this characteristic results in longer-term persistence of multiple episome copies in transfected cells as compared with other extrachromosomal plasmids. ${ }^{30}$ Most of the nonviral reprogramming protocols use electroporation to deliver the plasmids to somatic cells. In this study, the electroporation-based nonviral reprogramming protocol originally developed by the Thomson Group was adapted to generate human iPSClike cells from IMR-90 fibroblasts. ${ }^{4}$ As in the case of PBAE nanoparticles, the electroporation conditions were optimized for IMR-90 fibroblasts by varying the electroporation parameters, specifically the electroporation voltage (Figure 7).

We used an electroporation-based approach and a nanoparticle-based approach to develop EBNA-1/oriP episomal plasmid based feeder-independent reprogramming protocols to generate iPSC-like cell lines from human fibroblasts (Figure 8). The EP1 line generated by the electroporation approach was positive for pluripotency markers (Oct4, SSEA4, and Tra-1-60) and showed a normal female karyotype (Figure 9). The two EP2 lines generated by the nanoparticle-based reprogramming approach that were characterized by karyotyping were positive for pluripotency markers (Oct4, SSEA4, and Tra-1-60); however, they acquired significant karyotypic abnormalities (Figure 10). The EP1 colonies emerged as early as 30 days post-electroporation as determined by Tra-1-60 live staining protocol, following which time we switched from trypsin to Accutase for routine cell passaging. Tra-1-60 live staining has been reliably used to identify pluripotent iPSC-like cells. ${ }^{31}$ Nanoparticle-derived Tra-1-60-positive EP2 colonies emerged only around day 75 after the first transfection dose of T3/B4S4E7 nanoparticles (15 $\mu \mathrm{g}$ and $60 \mathrm{wt} / \mathrm{wt}$ dose per well). Therefore, the EP2 colonies, which were slower to reprogram, were exposed to trypsin for a longer period of time, ie, around 2.5 months, compared with EP1 colonies that were exposed to trypsin for about 1 month. Reprogramming stress induced by oncogenic factors and long-term exposure to trypsin during in vitro culture have been shown to increase the susceptibility of fibroblasts to chromosomal mutations. ${ }^{32,33}$ Trypsin passaging may contribute to preferential selection of karyotypically abnormal cells within the culture, which are initially rare but over time acquire a growth advantage over normal cells due to mutations that favor their survival

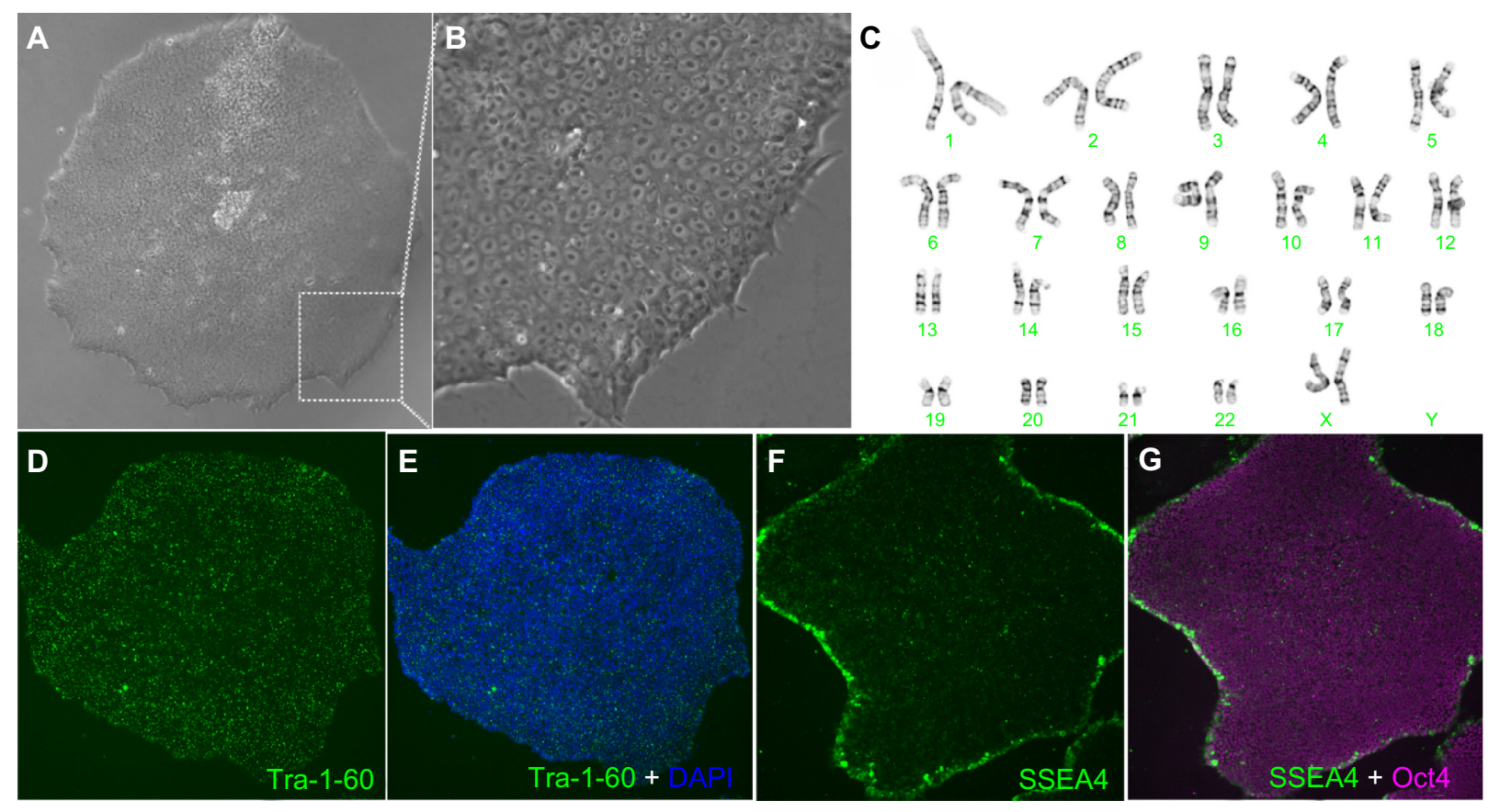

Figure 9 Characterization of EPI-hiPSC-like cell line generated by electroporation of nonintegrating episomal plasmids. Normal morphology is observed at low (A) and high (B) magnification. A normal karyotype is seen in (C). Immunolabeling with markers for pluripotency are shown (D-G).

Abbreviation: hiPSC, human induced pluripotent stem cells; DAPI, 4',6-diamidino-2-phenylindole. 

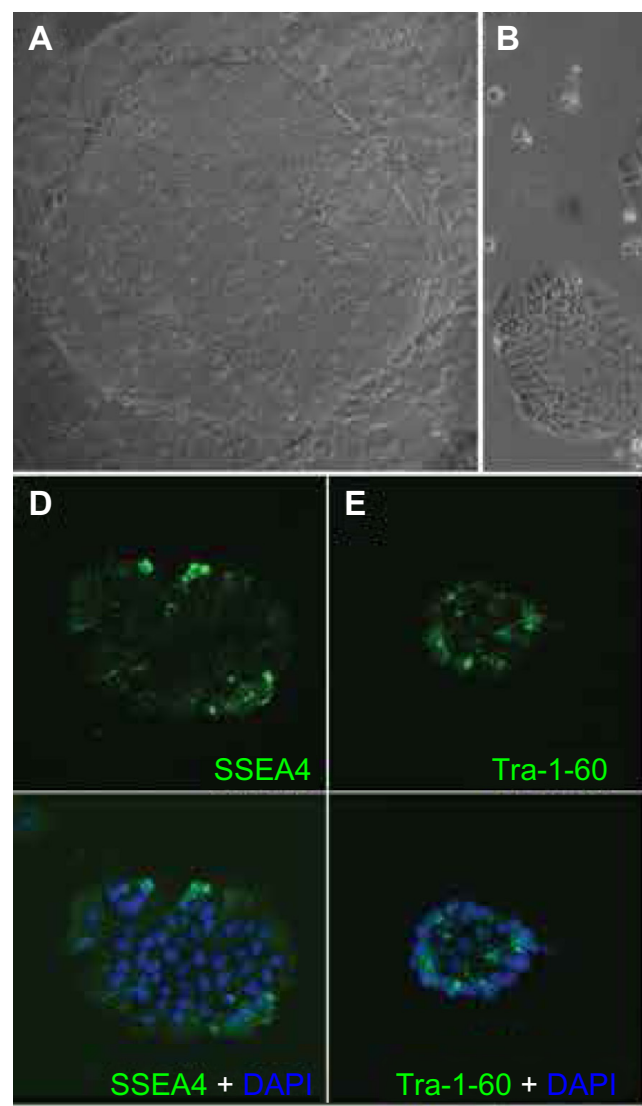

F
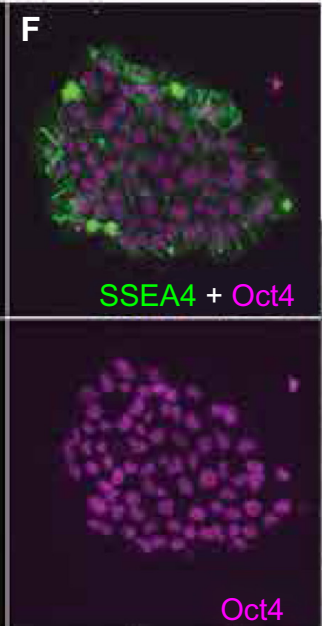
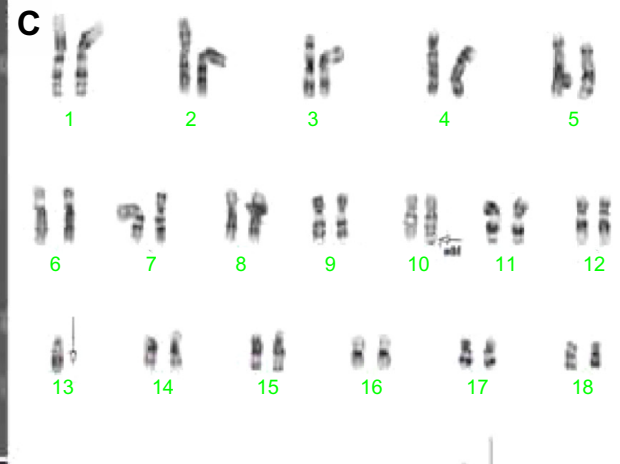

*

a

Clone 1

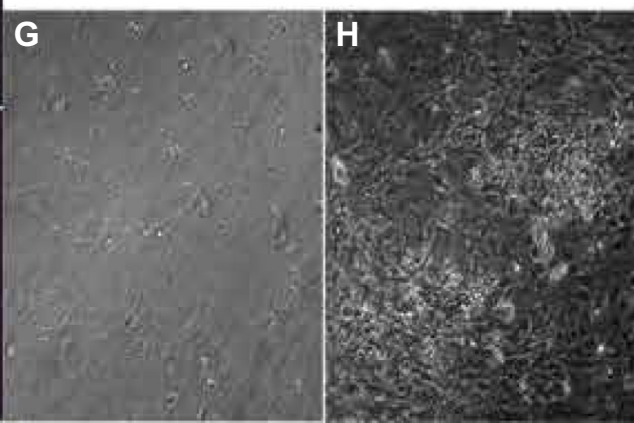

Figure 10 Characterization of EP2-iPSC-like cell line generated by PBAE nanoparticles. Normal morphology is observed in (A) pre-purified and (B) post-purified iPSC-like cells. An abnormal karyotype is seen in (C) (arrows). Immunolabeling with pluripotency markers is shown (D-F). Partial neuronal differentiation of EP2-iPSC-like cell line with regional variation ( $\mathbf{G}$ and $\mathbf{H})$.

Abbreviations: iPSC, induced pluripotent stem cells; PBAE, poly(beta-amino ester); DAPI, 4',6-diamidino-2-phenylindole.

and growth during reprogramming. The effect of long-term exposure of human pluripotent stem cells to Accutase has not been widely investigated, but a recent study by Stover and Schwartz reported no abnormalities in the karyotype after $>20$ passages. ${ }^{34}$ The lower reprogramming efficacy with B4S4E7/T3 nanoparticles, despite their high transfection efficacy with the B4S4E7/EGFP reporter nanoparticles, suggests that increasing the number of transfected cells is not sufficient for successful reprogramming.

\section{In vitro neural differentiation assay}

We next tested the ability of our iPSC-like lines to generate neuronal cell lineages. We subjected the iPSC-like lines to a stepwise neuronal induction protocol adapted from Meyer et al, that gives rise to retinal neurons and higher order forebrain-like neurons, ${ }^{27}$ because we were interested in modeling retinal degeneration (Figure 11A). The EP1 and EP2 colonies were clump-passaged in mTeSR1 containing blebbistatin and transitioned to a neural induction medium containing DMEM:F12 (1:1), N2 supplement, $1 \times$ nonessential amino acids, and heparin sulfate. After 5 days in suspension in non-tissue culture (TC)-coated dishes, embryoid bodies were plated onto Matrigel-coated dishes for an additional 7-9 days. During this time, conspicuous rosettes formed spontaneously in the EP1 electroporationderived iPSC-like line (Figure 11B) but failed to appear in either the EP2.1 or EP2.2 polymer-derived lines (Figure 10F and $\mathrm{G})$, indicating a failure to differentiate into neurons. On days 13-15, EP1 neural rosettes were mechanically lifted and maintained as neurospheres in DMEM:F12 (3:1), B27 and $1 \times$ nonessential amino acids in non-TC coated dishes. Following dissociation of 1-month-old neurospheres, dissociated neurons acquired a highly branched neuronal morphology, with neural connections, and expressed multiple neuronal markers, including Pax6 and Tuj1 (Figure 11E-G). Such cells were never observed in the polymer-derived EP2.1 and EP2.2 lines. In addition to the more general neuronal markers, retinal structures were also seen, including pseudostratified neuroepithelial optic cups (Figure 11H) and retinal pigment epithelium (Figure 11I and J).

The presence of the oncogene, cMyc, in the reprogramming cocktail limits the clinical use of derived human 

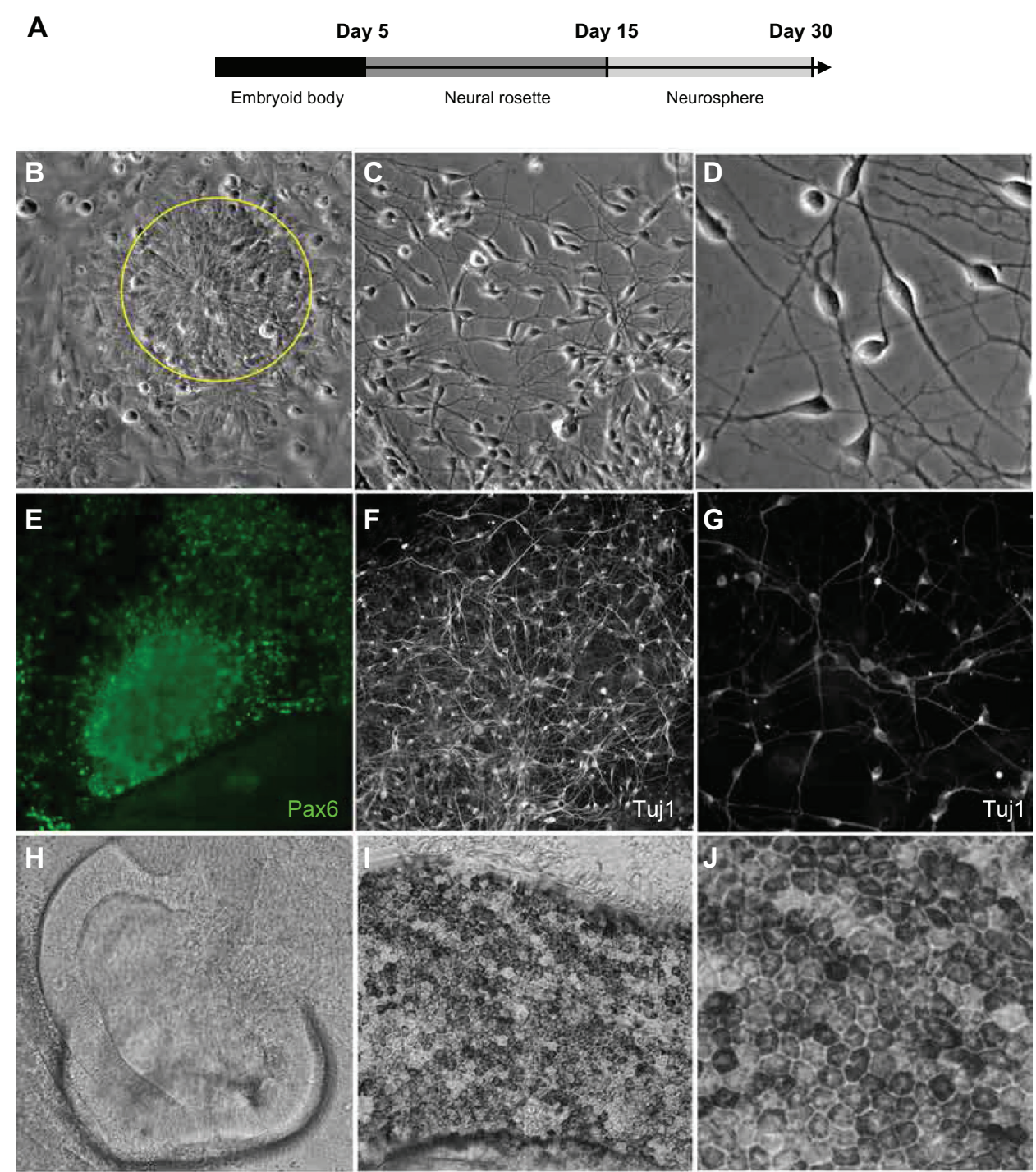

Figure I I Neuronal differentiation of EPI-iPSC-like cell line generated by electroporation (A). Neural rosettes (B) (indicated by yellow circle) and mature neurons (C) low and (D) high magnification can be generated from these cells. Immunostaining with markers for neuronal lineages, Pax6 and Tujl, are shown in (E), (F) low, and (G) high magnifications. Retinal structures including pseudostratified neuroepithelial optic cups $(\mathbf{H})$ and retinal pigment epithelium low $(\mathbf{I})$ and high $(\mathbf{J})$ magnifications can also be generated.

Abbreviation: iPSC, induced pluripotent stem cells.

iPSC-like cells. ${ }^{35}$ Moreover, sustained expression of any residual transgenic factors in derived human iPSC-like colonies post-reprogramming may hinder the downstream differentiation capacity of these cells. ${ }^{36,37}$ Montserrat et al have shown that other PBAE-based nanoparticles can be used to reprogram somatic cells to human iPSCs, but their approach was feeder-dependent, which is undesirable for clinically relevant applications, and they reported integration of the transgene in the backbone, which introduces the risk of insertional mutagenesis and tumorigenicity. ${ }^{38}$ Their study did not compare the PBAE-based method with the standard electroporation approach used for nonviral reprogramming.

Although our results demonstrate some of the potential limitations of nanoparticle-based generation of human
iPSC-like cells, there may be modifications of the approach that will be more amenable to successful generation of human iPSCs. Some of the problems we noted might be, in part, due to the slow reprogramming process with PBAEs. Thus, a faster protocol such as conversion of human patient-specific pluripotent stem cells and fibroblasts directly to retinal photoreceptors by forced expression of photoreceptor-expressed transcription factors might be more suitable to the use of these nanoparticles. Cord blood cells and keratinocytes have been shown to be more amenable for reprogramming, in terms of speed and efficiency, than skin fibroblasts. ${ }^{39,40}$ Cord blood cells have a high population of progenitor stem cells, and the keratinocyte is an epithelial cell type similar to the embryonic stem cell, whereas dermal fibroblasts (especially 


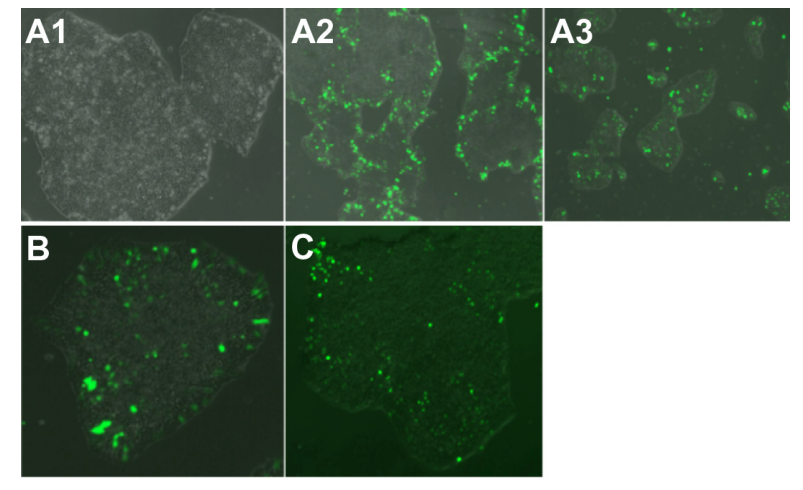

Figure I 2 Fluorescence microscopy images (I0X) of hiPSC-like cells transfected with a single dose of B4S4E7/EGFP nanoparticles. Images show healthy morphology posttransfection (AI), an edge effect in larger colonies (A2), and middle-transfected + edge-transfected cells in smaller colonies (A3). Image (20x) of hiPSC-like colony transfected with (B) two doses of B4S4E7 and EGFP complexes and (C) one dose with B4S4E7 and PiggyBac 2 plasmid system complexes.

Notes: Acrylate monomers (Bx), amino-alcohol monomers (Sy), and end-capping groups (Ez). The number " $x$ " following the acrylate monomers " $B$ " refers to the number of carbons between acrylate groups in the monomer, the number " $y$ " following the amino-alcohol monomers " $\mathrm{S}$ " refers to the number of carbons between the amine group and the alcohol group in the sidechain, and the number " $z$ " following the end-capping groups "E" refers to an arbitrary number used to designate a particular end-capping group.

Abbreviations: hiPSC, human induced pluripotent stem cells; EGFP, enhanced green fluorescent protein.

adult) are differentiated mesenchymal cells that are close to senescence, ${ }^{41,42}$ can possess somatic mutations, ${ }^{43,44}$ and have to undergo mesenchymal to epithelial transition during reprogramming. Although in this study PBAE nanoparticles were developed to transfect fetal as well as adult fibroblasts, similar PBAE nanoparticles have the potential to transfect epithelial cell types as well as blood cells..$^{23,45-47}$ Increased reprogramming efficacy with these more amenable cell types would help to reduce the in vitro culture time and thereby reduce the risk of elevating the chromosomal mutation rate during nanoparticle-based reprogramming. PBAEs specifically designed for transporting nucleic acid cargo to the cytoplasm could potentially be used to deliver mRNA coding for the reprogramming factors to fibroblasts or umbilical cord endothelial cells. ${ }^{46} \mathrm{mRNA}$ delivery is safer than gene delivery because there is no risk of insertional mutagenesis associated with the cytoplasmic delivery of mRNA. Synthetic mRNA designed to escape the cell's innate anti-RNA response allows high expression of reprogramming factor proteins in human fibroblasts. Significantly better reprogramming efficacy may be achieved with the mRNA technique, which has been reported to be more efficient and twice as fast as the gene delivery technique. ${ }^{15}$

The B4S4E7/EGFP nanoparticles were able to transfect human fetal lung fibroblasts, dermal fibroblasts derived from a patient with retinitis pigmentosa, and end-stage iPSClike populations (Figure 12). With further development,
B4S4E7-based nanoparticles may potentially be used for programming studies to differentiate these target populations to photoreceptors. The ability to create pools of customized photoreceptors could facilitate drug screening efforts targeting new human models for retinitis pigmentosa.

\section{Conclusion}

This study demonstrates that nanoparticles formed by self-assembly of 1-(3-aminopropyl)-4-methylpiperazine end-terminated poly (1,4-butanediol diacrylate-co-4-amino1-butanol) polymer (B4S4E7) with episomal plasmid DNA are more effective than leading commercially available reagents, including Lipofectamine 2000, FuGENE HD, and $25 \mathrm{kDa}$ branched polyethylenimine, for nonviral gene transfer to IMR-90 human primary fibroblasts and dermal fibroblasts derived from a patient with retinitis pigmentosa. The fibroblasts were reprogrammed with both polymeric nanoparticle-based and electroporation based nonviral gene delivery methods. Although human iPSC-like cells derived by both methods stained positively for the pluripotency markers Tra-1-60, SSEA4, and Oct4, the electroporation method generated EP1-iPSC-like cells with a normal karyotype in a shorter time period, whereas the nanoparticle-based reprogramming method took longer and generated EP2-iPSC-like cells with gross karyotypic abnormalities. These results suggest that certain nonviral reprogramming methods may pose safety risks and be less efficacious than viral approaches. The karyotypically normal EP1-human iPSC-like cells generated by conventional electroporation, but not by PBAE reprogramming, were successfully differentiated in vitro toward the early retinal lineage for disease modeling and drug screening to study retinal degeneration.

\section{Author contributions}

NSB, KJW, DJZ, and JJG designed the study. DJZ and JJG supervised the project. NSB and KJW performed the reprogramming experiments and pluripotency analysis. NSB performed the nanoparticle synthesis and characterization experiments and KJW performed the neuronal differentiation experiments. NSB, KJW, DJZ, and JJG wrote and edited the paper.

\section{Acknowledgments}

This work was supported by the Technology Development Corporation Maryland Stem Cell Research Fund (2009-MSCRFE-0098-00), the National Institutes of Health (1R01EB016721 and R01EY009769), a Foundation Fighting Blindness Wynn-Gund Translational Acceleration Program 
grant, core grant P30EY001765 to the Wilmer Eye Institute, unrestricted funds from Research to Prevent Blindness Inc, and generous gifts from Mr Robert and Mrs Clarice Smith and the Guerrieri Family Foundation. KJW was supported by a post-doctoral fellowship grant from the Maryland Stem Cell Research Fund.

\section{Disclosure}

The authors report no conflicts of interest in this work.

\section{References}

1. Murakami Y, Matsumoto H, Roh M, et al. Receptor interacting protein kinase mediates necrotic cone but not rod cell death in a mouse model of inherited degeneration. Proc Natl Acad Sci U S A. 2012;109(36): 14598-14603.

2. Jin ZB, Okamoto S, Mandai M, Takahashi M. Induced pluripotent stem cells for retinal degenerative diseases: a new perspective on the challenges. J Genet. 2009;88(4):417-424.

3. Takahashi K, Tanabe K, Ohnuki M, et al. Induction of pluripotent stem cells from adult human fibroblasts by defined factors. Cell. 2007;131(5): 861-872.

4. $\mathrm{Yu} \mathrm{J}, \mathrm{Hu} \mathrm{K}$, Smuga-Otto K, et al. Human induced pluripotent stem cells free of vector and transgene sequences. Science. 2009;324(5928):797-801.

5. Verma IM, Somia N. Gene therapy - promises, problems and prospects. Nature. 1997;389(6648):239-242.

6. Hollon T. Researchers and regulators reflect on first gene therapy death. Am J Ophthalmol. 2000;129(5):701.

7. Check E. Gene therapy put on hold as third child develops cancer. Nature. 2005;433(7026):561.

8. Cavazzana-Calvo M, Thrasher A, Mavilio F. The future of gene therapy. Nature. 2004;427(6977):779-781

9. Yu J, Hu K, Smuga-Otto K, et al. Human induced pluripotent stem cells free of vector and transgene sequences. Science. 2009;324(5928) 797-801.

10. Chou BK, Mali P, Huang X, et al. Efficient human iPS cell derivation by a non-integrating plasmid from blood cells with unique epigenetic and gene expression signatures. Cell Res. 2011;21(3):518-529.

11. Li W, Jiang K, Ding S. A chemical approach to controlling cell fate and function. Stem Cells. 2012;30(1):61-68.

12. Narsinh KH, Jia F, Robbins RC, Kay MA, Longaker MT, Wu JC. Generation of adult human induced pluripotent stem cells using nonviral minicircle DNA vectors. Nat Protoc. 2011;6(1):78-88.

13. Kim D, Kim CH, Moon JI, et al. Generation of human induced pluripotent stem cells by direct delivery of reprogramming proteins. Cell Stem Cell. 2009;4(6):472-476.

14. Zhou H, Wu S, Joo JY, et al. Generation of induced pluripotent stem cells using recombinant proteins. Cell Stem Cell. 2009;4(5):381-384.

15. Warren L, Manos PD, Ahfeldt T, et al. Highly efficient reprogramming to pluripotency and directed differentiation of human cells with synthetic modified mRNA. Cell Stem Cell. 2010;7(5):618-630.

16. Okita K, Yamanaka S. Induced pluripotent stem cells: opportunities and challenges. Philos Trans R Soc Lond B Biol Sci. 2011;366(1575): 2198-2207.

17. Gheisari Y, Soleimani M, Azadmanesh K, Zeinali S. Multipotent mesenchymal stromal cells: optimization and comparison of five cationic polymer-based gene delivery methods. Cytotherapy. 2008;10(8): 815-823.

18. Yalvac ME, Ramazanoglu M, Gumru OZ, Sahin F, Palotas A, Rizvanov AA. Comparison and optimisation of transfection of human dental follicle cells, a novel source of stem cells, with different chemical methods and electro-poration. Neurochem Res. 2009;34(7): $1272-1277$.
19. Srinivasan C, Burgess DJ. Optimization and characterization of anionic lipoplexes for gene delivery. J Control Release. 2009;136(1):62-70.

20. Lynn DM, Langer R. Degradable poly(beta-amino esters): Synthesis, characterization, and self-assembly with plasmid DNA. J Am Chem Soc. 2000;122(44):10761-10768.

21. Bhise NS, Shmueli RB, Gonzalez J, Green JJ. A novel assay for quantifying the number of plasmids encapsulated by polymer nanoparticles. Small. 2012;8(3):367-373.

22. Green JJ, Zugates GT, Tedford NC, et al. Combinatorial modification of degradable polymers enables transfection of human cells comparable to adenovirus. Adv Mater. 2007;19(19):2836-2842.

23. Bhise NS, Gray RS, Sunshine JC, Htet S, Ewald AJ, Green JJ. The relationship between terminal functionalization and molecular weight of a gene delivery polymer and transfection efficacy in mammary epithelial 2-D cultures and 3-D organotypic cultures. Biomaterials. 2010;31(31):8088-8096.

24. Sunshine JC, Akanda MI, Li D, Kozielski KL, Green JJ. Effects of base polymer hydrophobicity and end-group modification on polymeric gene delivery. Biomacromolecules. 2011;12(10):3592-3600.

25. Tzeng SY, Guerrero-Cazares H, Martinez EE, Sunshine JC, QuinonesHinojosa A, Green JJ. Non-viral gene delivery nanoparticles based on poly(beta-amino esters) for treatment of glioblastoma. Biomaterials. 2011;32(23):5402-5410.

26. Sunshine J, Bhise N, Green JJ. Degradable polymers for gene delivery. Conf Proc IEEE Eng Med Biol Soc. 2009;2009:2412-2415.

27. Meyer JS, Shearer RL, Capowski EE, et al. Modeling early retinal development with human embryonic and induced pluripotent stem cells. Proc Natl Acad Sci U S A. 2009;106(39):16698-16703.

28. Synnergren J, Giesler TL, Adak S, et al. Differentiating human embryonic stem cells express a unique housekeeping gene signature. Stem Cells. 2007;25(2):473-480.

29. Hochedlinger K, Plath K. Epigenetic reprogramming and induced pluripotency. Development. 2009;136(4):509-523.

30. Hung SC, Kang MS, Kieff E. Maintenance of Epstein-Barr virus (EBV) oriP-based episomes requires EBV-encoded nuclear antigen-1 chromosome-binding domains, which can be replaced by high-mobility group-I or histone H1. Proc Natl Acad Sci U S A. 2001;98(4): 1865-1870.

31. Mali P, Ye Z, Chou BK, Yen J, Cheng L. An improved method for generating and identifying human induced pluripotent stem cells. Methods Mol Biol. 2010;636:191-205.

32. Hasegawa K, Fujioka T, Nakamura Y, Nakatsuji N, Suemori H. A method for the selection of human embryonic stem cell sublines with high replating efficiency after single-cell dissociation. Stem Cells. 2006; 24(12):2649-2660.

33. Ji J, Ng SH, Sharma V, et al. Elevated coding mutation rate during the reprogramming of human somatic cells into induced pluripotent stem cells. Stem Cells. 2012;30(3):435-440.

34. Stover AE, Schwartz PH. Adaptation of human pluripotent stem cells to feeder-free conditions in chemically defined medium with enzymatic single-cell passaging. Methods Mol Biol. 2011;767:137-146.

35. Nakagawa M, Koyanagi M, Tanabe K, et al. Generation of induced pluripotent stem cells without Myc from mouse and human fibroblasts. Nat Biotechnol. 2008;26(1):101-106.

36. Ramos-Mejia V, Montes R, Bueno C, et al. Residual expression of the reprogramming factors prevents differentiation of iPSC generated from human fibroblasts and cord blood CD34+ progenitors. PLoS One. 2012;7(4):e35824

37. Sommer CA, Sommer AG, Longmire TA, et al. Excision of reprogramming transgenes improves the differentiation potential of iPS cells generated with a single excisable vector. Stem Cells. 2010;28(1): 64-74.

38. Montserrat N, Garreta E, Gonzalez F, et al. Simple generation of human induced pluripotent stem cells using poly-beta-amino esters as the non-viral gene delivery system. J Biol Chem. 2011;286(14): 12417-12428.

39. Giorgetti A, Montserrat N, Aasen T, et al. Generation of induced pluripotent stem cells from human cord blood using OCT4 and SOX2. Cell Stem Cell. 2009;5(4):353-357. 
40. Aasen T, Raya A, Barrero MJ, et al. Efficient and rapid generation of induced pluripotent stem cells from human keratinocytes. Nat Biotechnol. 2008;26(11):1276-1284.

41. Goldstein S. Replicative senescence: the human fibroblast comes of age. Science. 1990;249(4973):1129-1133.

42. Yoon IK, Kim HK, Kim YK, et al. Exploration of replicative senescenceassociated genes in human dermal fibroblasts by cDNA microarray technology. Exp Gerontol. 2004;39(9):1369-1378.

43. Chen J, Shi ZP, Dong J, et al. Evaluation of x-inactivation status and cytogenetic stability of human dermal fibroblasts after long-term culture. Int J Cell Biol. 2010;2010:289653.

44. Allahbakhshian-Farsani M, Abdian N, Ghasemi-Dehkordi P, et al. Cytogenetic analysis of human dermal fibroblasts (HDFs) in early and late passages using both karyotyping and comet assay techniques. Cytotechnology. August 31, 2013. [Epub ahead of print.]
45. Shmueli RB, Sunshine JC, Xu Z, Duh EJ, Green JJ. Gene delivery nanoparticles specific for human microvasculature and macrovasculature. Nanomedicine. 2012;8(7):1200-1207.

46. Tzeng SY, Yang PH, Grayson WL, Green JJ. Synthetic poly(ester amine) and poly(amido amine) nanoparticles for efficient DNA and siRNA delivery to human endothelial cells. Int J Nanomedicine. 2011;6:3309-3322.

47. Tzeng SY, Hung BP, Grayson WL, Green JJ. Cystamine-terminated poly(beta-amino ester)s for siRNA delivery to human mesenchymal stem cells and enhancement of osteogenic differentiation. Biomaterials. 2012;33(32):8142-8151.

\section{Publish your work in this journal}

The International Journal of Nanomedicine is an international, peerreviewed journal focusing on the application of nanotechnology in diagnostics, therapeutics, and drug delivery systems throughout the biomedical field. This journal is indexed on PubMed Central, MedLine, CAS, SciSearch $\AA$, Current Contents ${ }^{\circledR} /$ Clinical Medicine,
Journal Citation Reports/Science Edition, EMBase, Scopus and the Elsevier Bibliographic databases. The manuscript management system is completely online and includes a very quick and fair peer-review system, which is all easy to use. Visit http://www.dovepress.com/ testimonials.php to read real quotes from published authors. 